\title{
MEWMA CONTROL CHART PROCEDURE: AVERAGE RUN LENGTH PERFORMANCE WITH APPLICATON
}

\author{
M. S. HAMED \\ Department of Applied Statistics \\ Faculty of Commerce \\ Benha University \\ Egypt \\ e-mail: moswilem@gmail.com
}

\begin{abstract}
Statistical control chart is one of the most powerful tools in quality control. It was first developed by Walter Shewhart in 1920. It found widespread use in World War II and since then it has gone through several modification. The main drawback of multivariate charting schemes is their inability to identify which variable was the source of the signal. The multivariate exponentially weighted moving average (MEWMA) developed by Lowry et al. [2] is an example of a multivariate charting scheme whose monitoring statistic is unable to determine which variable caused the signal. In this paper, the run length performance of multivariate exponentially weighted moving average (MEWMA) chart with application is studied. Industry fertilizers is important one of the chemical industries in Egypt, so that this work concerns the fertilizers industries quality control, especially urea fertilizer with application on Delta fertilizer and chemical industries which is considered on of the leading companies in the field of fertilizer production in Middle east with application of multivariate quality control procedures to achieve best one procedure for multivariate quality control.
\end{abstract}

2010 Mathematics Subject Classification: 62P30, 62H99.

Keywords and phrases: MEWMA (multivariate exponentially weighted moving average), multivariate analysis, quality control.

Received June 25, 2016; Revised July 7, 2016

(C) 2016 Scientific Advances Publishers 


\section{Introduction}

Statistical control chart is one of the most powerful tools in quality control. It was first developed by Walter Shewhart in 1920. It found widespread use in World War II and since then it has gone through several modification. With today's use of computers, it is common to monitor several correlated quality characteristics simultaneously. Various types of multivariate control charts have been proposed to take advantage of the relationships among the variables being monitored. Alt [5], Jackson [9], Lowry and Montgomery [1], and Mason et al. [15] discuss much of the literature on this topic. The formatter will need to create these components, incorporating the applicable criteria that follow.

\section{Procedure}

The EWMA techniques give the most recent observation the greatest weight with all previous observations weights decreasing in a geometric (exponential) progression from the recent back to the first. Timm [8] developed a control chart by using the EWMA to control a process mean. To demonstrate the EWMA technique, suppose that we observe sample means $X_{1}, X_{2}, X_{3}, \ldots$ in the univariate case, where

$$
X \sim N\left(\mu_{0}, \sigma_{x}^{2}\right)
$$

MacGregor and Kourti [12] introduced the univariate exponentially weighed moving average (EWMA) control chart:

$$
Z_{i}=r X_{i}+(1-r) Z_{i-1}, \quad i=1,2,3, \ldots,
$$

where $r$ is a smoothing constant and $Z_{i}$ is the value of the EWMA after observation $i$, where $i$ represents the observation number as well as an index of a point in time, where we required $Z_{0}=\mu_{0}=0$ without loss of generality and $0<r \leq 1$. 
Further he supposed that if $X_{1}, X_{2}, X_{3}, \ldots$ are independently and identically distributed $N\left(0, \sigma^{2}\right)$ random variables, the mean of $Z_{i}$ is 0 and the variance is

$$
\operatorname{var}\left(Z_{i}\right)=\sigma_{Z}^{2}=\left\{\frac{r\left[1-(1-r)^{2 i}\right.}{2-r}\right\} \sigma \frac{2}{X}, \quad i=1,2,3, \ldots
$$

He suggested that when the in-control value of the mean is 0 , the control limits of the EWMA chart are at $\pm L \sigma_{Z i}$, where $L$ and $r$ are the parameters of the chart.

Lucas and Saccucci [13] have analyzed that the choice of $L$ and $r$ for the interval $(0.05 \leq 0.25)$ work well in practice, with $r=0.05, r=0.10$, and $r=0.20$ being popular choices. Thumb rule method is to use smaller values of $r$ to detect smaller shifts. They have also found that $L=3$ (the usual three - sigma limits) works although when $r$ is small - say, $r \leq 0.1$ - there is an advantage in reducing the width of the limits by using a value of $L$ between about 2.6 and 2.8 although their control limits, were based on the asymptotic form of $\sigma_{Z i}$ which is given by $\sigma_{Z i} \cong \sigma_{X} \sqrt{\frac{r}{2-r}}$.

\section{EWMA Control Chart: Multivariate Extension}

Lowry et al. [2] has generalized the concept of the univariate EWMA control chart to the multivariate case. They defined the MEWMA vectors as:

$$
Z_{i}=R X_{i}+(1-R) Z_{i-1}, i=1,2,3, \ldots
$$

where $Z_{0}=0$ and

$$
R=\operatorname{diag}\left(r_{1}, r_{2}, \ldots, r_{p}, 0<r_{j} \leq 1\right), \quad j=1,2, \ldots, p \text { and } p>1 .
$$


The MEWMA control chart gives an out of control signal as soon as:

$$
T_{i}^{2}=Z_{i}^{\prime} \sum_{i}^{-1} Z_{i}>L
$$

where $L>0$ is chosen to achieve a specified in-control ARL, and $\sum_{Z i}$ is the covariance matrix of $Z_{i}$.

A technique to interpret the out-of-control signal and identify an assignable cause from a multivariate control chart is provided by Mason et al. [15]. Their method can be applied to MEWMA control chart. According to their method, it has been assumed that Phase I of process control is when the first subgroups are drawn from the process and little is known about the joint distribution of the quality characteristics. Phase II is when sufficient information is known about the process and subgroups are drawn to test if the process is in control. Often there is no reason to apply different exponential weights to past observations of the $p$ different quality characteristics. In this situation, Lowry et al. [2] assumed the equal weights across characteristics where $r=r_{j}, j=1, \ldots, p$, the MEWMA vectors can then be written as

$$
Z_{i}=r X_{i}+(1-r) Z_{i-1}, \quad i=1,2,3, \ldots
$$

Assuming equal weights, Lowry et al. [2] have shown that the covariance matrix of $Z_{i}$ can be written in terms of the exponential weight $r$ and the covariance matrix of the process data $\sum_{X}$ as:

$$
\sum_{Z i}=\left\{\frac{r\left[1-(1-r)^{2 i}\right.}{2-r}\right\} \sum_{X}
$$

Note that if $r=1$, the MEWMA chart is equivalent to Hotellin's $\mathrm{T}^{2}$ chart. 
When the process is likely to stay in-control for some time period, the asymptotic from of the covariance matrix $\sum_{X}$ used to calculate the MEWMA test statistic (Lowry et al. [2]):

$$
\sum_{Z i}=\left\{\frac{r}{2-r}\right\} \sum_{X}
$$

The use of exact variance of the EWMA statistic leads to a natural fast initial response for the EWMA chart (Lowry et al. [2]). Thus, the initial that, out-of-control conditions can also, applied to the MEWMA chart. Because, however, it may be more likely that the process will stay in-control for a while and then shift out-of-control, they assumed for chart design that the asymptotic (as $i \rightarrow \infty$ ) covariance matrix, is give by Equation (8). Linderman and Love [14] have pointed out that the use of exact covariance matrix and the asymptotic covariance matrix lead to two different procedures; actually, they have concentrated their efforts concerned solely on the MEWMA chart using the asymptotic covariance matrix and the exact covariance matrix. They have depended on the use of MEWMA chart in order to study the $p$ quality characteristics associated with a process. The process begins in the in-control state with mean vector $\mu_{0}=0$ and covariance matrix $\sum_{X}$. They supposed also that the process is subject to a single assignable cause, which shifts the process mean from $\mu_{0}$ to a point on the constant probability density contour $D$; defined by

$$
D=\left\lfloor\mu_{1} \mid \mu_{1}^{\prime} \sum_{X}^{-1} \mu_{1}=\delta^{2}\right\rfloor
$$

where $\delta$, the parameter describing the size of shift, is known. Note that Equation (9) is the constant probability density contour for a $p$-dimensional multivariate normal distribution. This contour forms an ellipsoid which is centered at $\mu_{0}$ and has axes $\pm \delta \sqrt{\xi_{j} e_{j}}$, where $\sum_{X} e_{j}=\xi_{j} e_{j}$, for $j=1, \ldots, p$. 
Khoo [3] has suggested that the main choice for the value of $r$ in Equations (7) and (8) is, founded on the magnitude of shift, where a quick detection is required. In general, small values of $r$ used for quick detection of small shifts, where as larger values of $r$ used for quick detection of large shifts. He has, also added that in case of $(i \rightarrow \infty)$ the exact covariance matrix in Equation (7) is approximately equal to the asymptotic covariance matrix in Equation (8); pointing out that this, the two covariance matrices in Equations (7) and (8) differ only in initial periods when $i$ values are small. However, the advantages of the exact MEWMA chart over the asymptotic MEWMA chart are that the exact MEWMA chart enables quicker detection of initial out-of-control conditions and is more sensitive for detecting shifts involving smaller values of $r$.

\section{Average Run Length (ARL) Performance}

The metric used to determine the control chart's ability in order to determine if the process is in-control or out-of-control is called the average run length. Lowry et al. [2] established that ARL performance for a MEWMA control chart is directionally invariant and determined solely by the non-centrality parameter. This means that the average run length depends only on the distance between the in-control and out-ofcontrol mean, and not on the direction. The non-centrality parameter given by Lowry et al. [2], as:

$$
\delta^{2}\left(\mu_{y}\right)=\left(\mu_{y}-\mu_{0}\right)^{\prime} \sum_{X}^{-1}\left(\mu_{y}-\mu_{0}\right)
$$

where $\mu_{y}$ is the mean when the process is out of control. They supposed that if $\mu_{i}=\mu, i=1,2, \ldots$, the non-centrality parameter is given as:

$$
\delta^{2}=\left(\mu^{\prime} \sum_{X}^{-1} \mu\right)
$$

Current researches have been developed to approximate the ARL for a MEWMA control chart. These methodologies have assumed that the in 
control distribution is given as $N_{p}\left(\mu_{0}, \sum_{X}\right)$. In addition, all these methodologies have made use of the ARL following fact that the performance depends only on the non-centrality parameter. As a result, to determine the ARL for a MEWMA control chart with an in-control distribution $N_{p}\left(\mu_{0}, \sum\right)$ and out-of-control distribution $N_{p}\left(\mu_{1}, \sum\right)$, we can determine the ARL performance of a MEWMA control chart with an in-control distribution $N_{p}(0,1)$ and out-of-control distribution $N_{p}\left(\mu_{\delta}, I\right)$, where $\mu_{\delta}=(\delta, 0, \ldots, 0)$. That is, the non-centrality parameter between both problems is identical.

Actually, the ARL performance, which only depends on the noncentrality parameter, is central to methodologies that have suggested to approximate ARL0 and ARL1 for a MEWMA chart. The approximation methodologies include simulation [9], a bivariate Markov chain method [16], and integral equation [15].

\section{Application}

Delta fertilizers and chemical industries is considered on of the leading companies in the field of fertilizers production in Egypt. About 4500 employees are working for it, on the various managerial levels. Urea production is one of the major products of the company. The production of urea occurs through three stages, summarized as follows:

\section{A. High pressure stage}

In this stage, urea is produced through two reactions; the first reaction occurs by condensation of ammonia gas and carbon dioxide under high pressure and temperature for the sake of the production of intermediate material, known as Carbamate. The second reaction happens by separating the water from the Carbamate in order to achieve urea. In this stage, the condensation of urea approximately $56 \%$. 
It contains 16 variables, these are:

X1 E-201 Outlet temperature

X2 Outlet cold $\mathrm{NH}_{3}$ from E-201

X3 $\quad \mathrm{CO}_{2}$ to Train

$\mathrm{X} 4 \quad \mathrm{CO}_{2}$ Pressure to synthesis

X5 $\quad \mathrm{CO}_{2}$ after E-22

X6 R-201

X7 Temperature in reactor R-201

X8 Temperature in reactor R-201

X9 Temperature in reactor R-201

X10 Temperature in reactor R-201

X11 Stripper level

X12 Liquid leaving the stripper

X13 Stream from E-204 to J-201

X14 Conditioned water to scrubber E-204

X15 Conditioned water from scrubber E-204

X16 Stream from J-203

Table analysis of laboratory in this stage:

$\begin{array}{ccc}\text { t1.1 } & \mathrm{NH}_{3} & \text { Reactor outlet } \\ \mathrm{t} 1.2 & \mathrm{CO}_{2} & \text { Reactor outlet } \\ \mathrm{t} 1.3 & \mathrm{UR} & \text { Reactor outlet } \\ \mathrm{t} 1.4 & \mathrm{~B}_{1} & \text { Reactor outlet } \\ \mathrm{t} 1.5 & \mathrm{H}_{2} \mathrm{O} & \text { Reactor outlet } \\ \mathrm{t} 2.1 & \mathrm{NH}_{3} & \text { Stripper outlet }\end{array}$




$\begin{array}{lll}\text { t2.2 } & \mathrm{CO}_{2} & \text { Stripper outlet } \\ \text { t2.3 } & \mathrm{UR} & \text { Stripper outlet } \\ \mathrm{t} 2.4 & \mathrm{~B}_{1} & \text { Stripper outlet } \\ \mathrm{t} 2.5 & \mathrm{H}_{2} \mathrm{O} & \text { Stripper outlet }\end{array}$

\section{B. Low pressure stage}

In this stage, the condensation of urea liquid rises from $56 \%$ to $71 \%$. This happens through the decomposition of the remaining Carbamate and the elimination of water under low pressure.

It contains seven variables, these are:

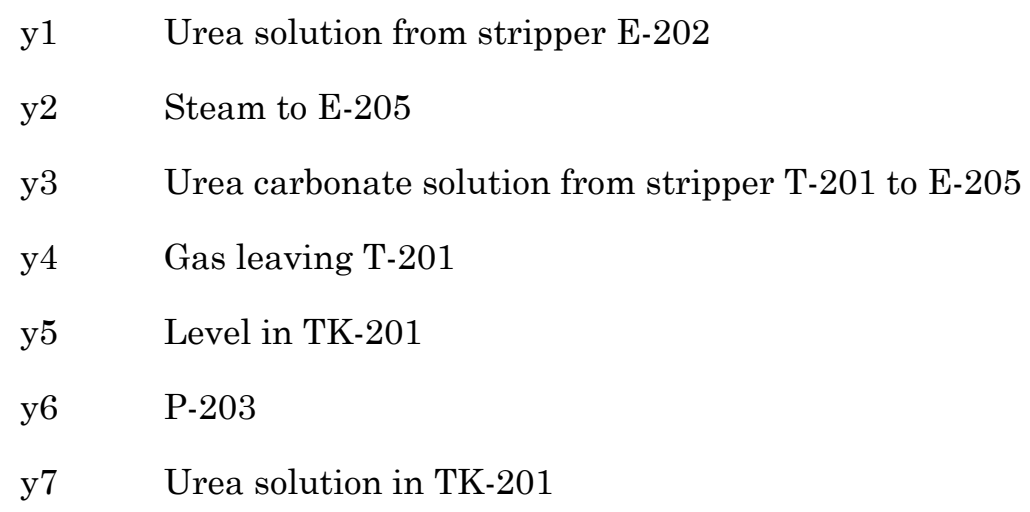

Table analysis of laboratory in this stage:

$\begin{array}{ccc}\text { t3.1 } & \mathrm{NH}_{3} & \text { D 202 Outlet } \\ \text { t3.2 } & \mathrm{CO}_{2} & \text { D 202 Outlet } \\ \text { t3.3 } & \mathrm{UR} & \text { D 202 Outlet } \\ \text { t3.4 } & \mathrm{B}_{1} & \text { D 202 Outlet } \\ \text { t3.5 } & \mathrm{H}_{2} \mathrm{O} & \text { D 202 Outlet } \\ \text { t4.1 } & \mathrm{NH}_{3} & \text { In TK 201 } \\ \text { t4.2 } & \mathrm{CO}_{2} & \text { In TK 201 }\end{array}$




$\begin{array}{lll}\mathrm{t} 4.3 & \mathrm{UR} & \text { In TK } 201 \\ \mathrm{t} 4.4 & \mathrm{~B}_{1} & \text { In TK } 201 \\ \mathrm{t} 4.5 & \mathrm{H}_{2} \mathrm{O} & \text { In TK } 201 \\ \mathrm{t} 5.1 & \mathrm{NH}_{3} & \text { In PI } 302 \\ \mathrm{t} 5.2 & \mathrm{CO}_{2} & \text { In PI } 302 \\ \mathrm{t} 5.3 & \mathrm{UR} & \text { In PI } 302\end{array}$

\section{Evaporation and prilling stage}

This stage occurs by two stage:

\section{(i) Evaporation stage}

In this stage, the condensation of urea rises from $71 \%$ to $98.7 \%$ approximately and the urea liquid trams forms to urea melt. This happens under high pressure and temperature.

\section{(ii) Prilling stage}

In this stage, the urea melt is through formed into prilling in the prilling tower.

It contains four variables, these are:

Z1 Urea solution from D-204 to E-209

Z2 D- 205 Vacuum

Z3 Urea to prilling tower X-202

Z4 E- 211 Vacuum

Table analysis of laboratory in this stage:
t6.1 B1
t6.2 $\quad \mathrm{H}_{2} \mathrm{O}$
t6.3 Pills $>3.35$
t6.4 Pills 3.35: 2.4 
t6.5 Pills $2.4: 1.4$

t6.6 Pills $1.4: 1.0$

t6.7 Pills $<1.0$

t6.8 UR

\subsection{Data description}

For the application of multivariate quality control, chart data originate from urea production process, which consists of the three stages and the analysis of laboratory, which discussed above.

The number of the sample is 732 observations taken per hour.

The advantages of this sample that, it has several variables and several stage of the production. This advantage of the production is the basic reason for choosing this production to allow us to study the multivariate quality control charts.

In this application, we shall introduce the most common using techniques of multivariate quality control chart; MEWMA.

A multivariate EWMA chart consists of:

- Plotted points, each of which represents the multivariate statistic for each observation.

- Upper control limits (red), which provide a visual means for assessing whether the process is in-control.

MINITAB marks points outside of the control limits with a red symbol.

We select combination of $r$ and ARL for plotting several MEWMA charts for each stage of the production study.

ARL and $r$ are the parameters of the MEWMA chart, the minimum allowable ARL is 1 and the value of $r$ must be a number between zero and one.

Note that the default value of $r=0.1$ and the default value of $A R L=200$. 


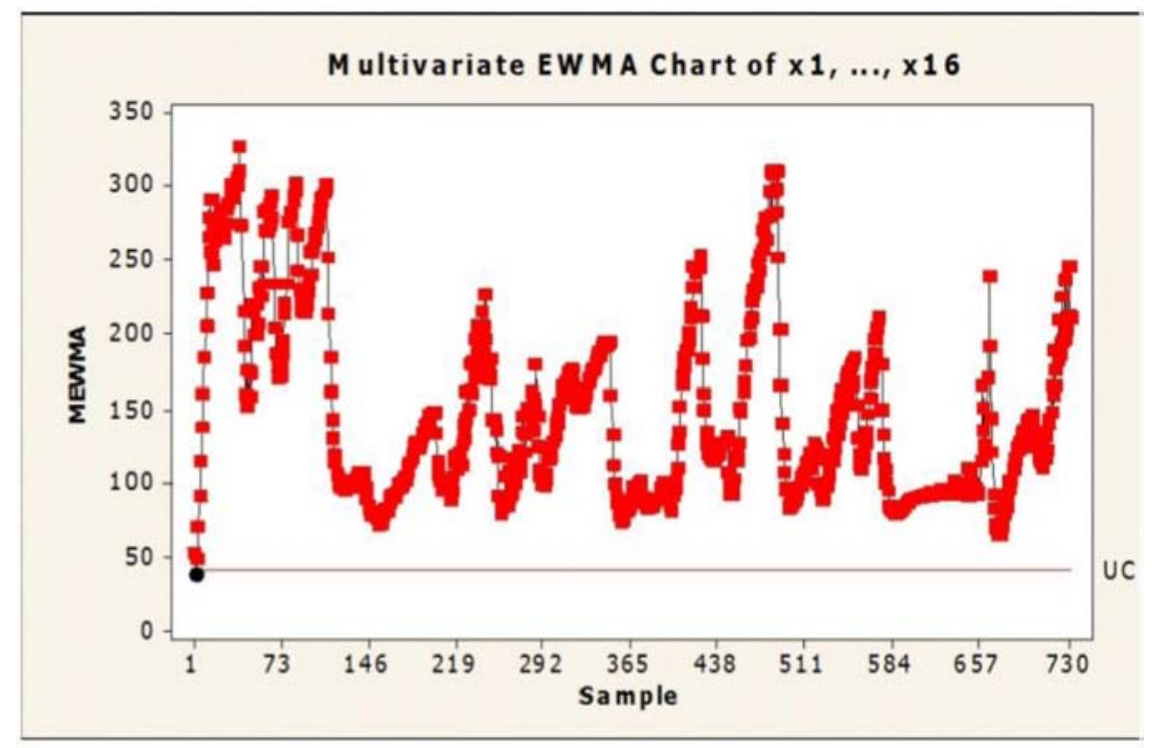

Figure 1. MEWMA chart of X1, .., X16 with ARL $=200, r=0.1$.

MEWMA chart of X1, .., X16 and t1.1,.., t2.5 (where ARL $=200$ and $r=0.1$ ) can be summarized as follows:

- The upper control limit is 40.0. Therefore, we expect the MEWMA statistics to fall below 40.0.

- Test results indicate that all points beyond the control limits except points 2 and 3 fall below the upper control limit.

- Test results indicate that the process is in-control for two points and out-of control for 730 points. Then the out-of-control rate $99.73 \%$ and the in-control rate $0.27 \%$. 


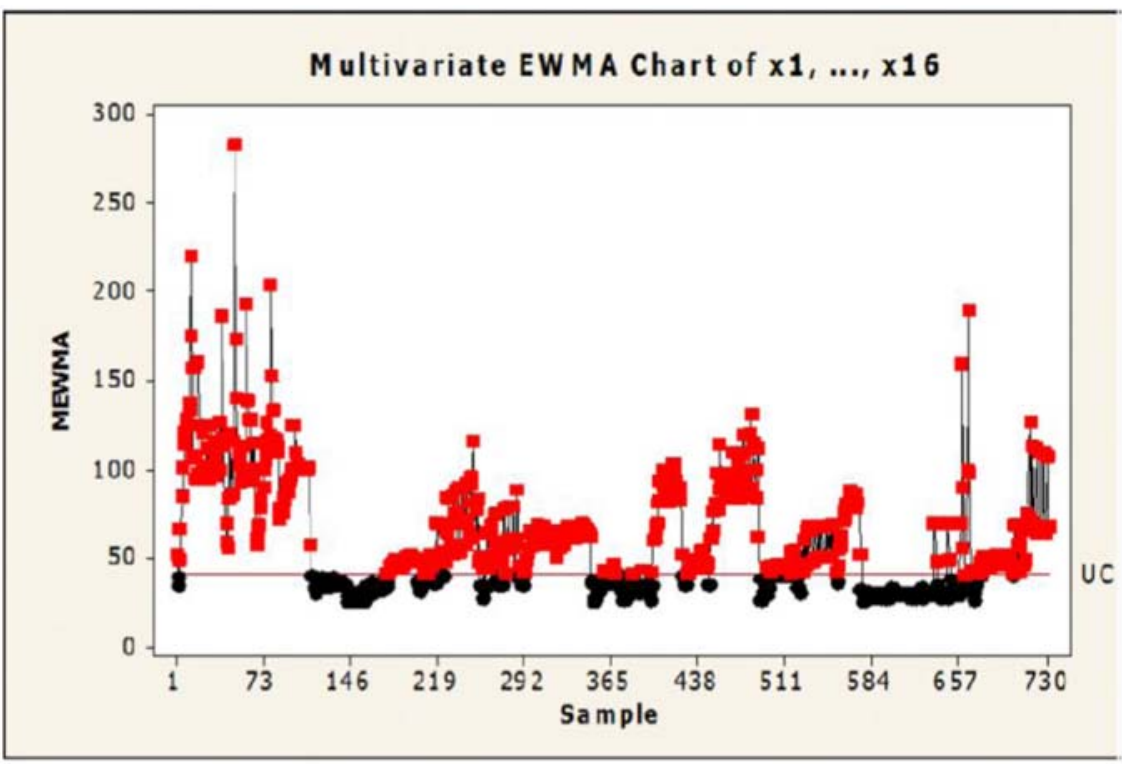

Figure 2. MEWMA chart of $\mathrm{X} 1, \ldots, \mathrm{X} 16$ with $\mathrm{ARL}=200, r=0.3$.

MEWMA chart of X1, .., X16 and t1.1,.., t2.5 (where ARL = 200 and $r=0.3)$ can be summarized as follows:

- The upper control limit is 40.5. Therefore, we expect the MEWMA statistics to fall below 40.5.

- Test results indicate that 491 points beyond the control limits.

- Test results indicate that the process is in-control for 241 points and out-of control for 491 points. Then the out-of-control rate $67.08 \%$ and the in-control rate $32.92 \%$. 


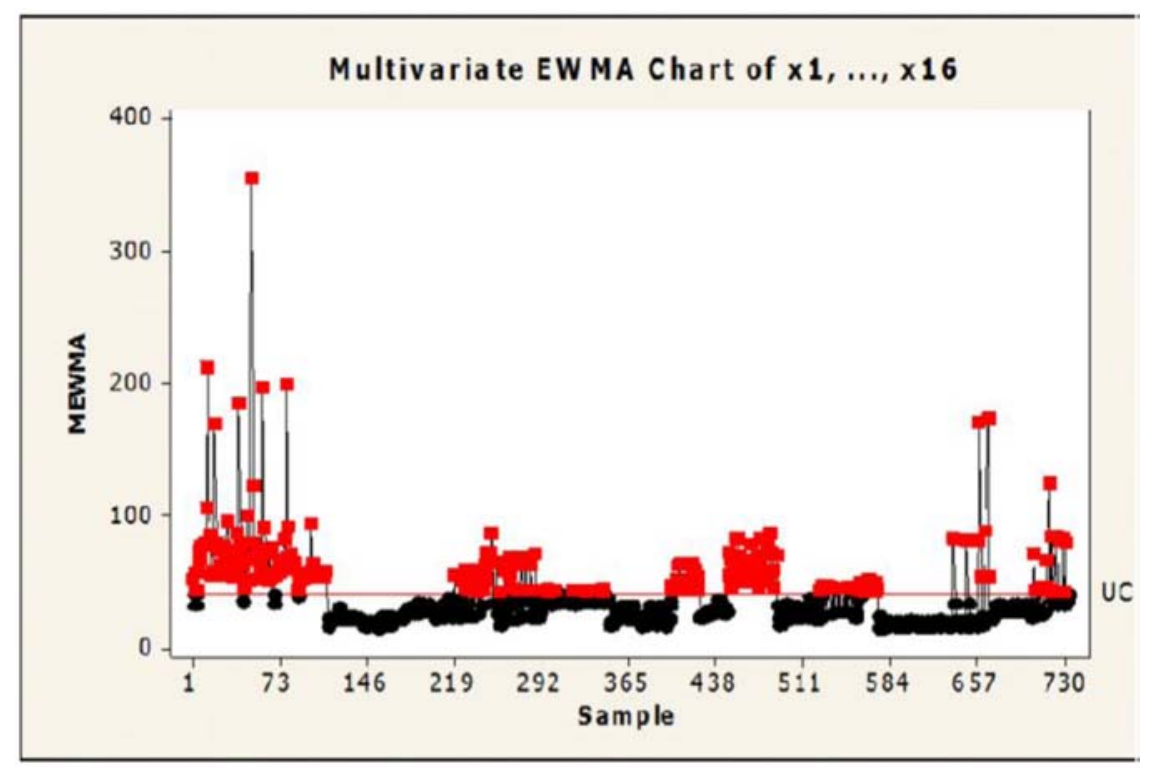

Figure 3. MEWMA chart of $\mathrm{X} 1, \ldots, \mathrm{X} 16$ with $\mathrm{ARL}=200, r=0.5$.

MEWMA chart of X1, .., X16 and t1.1,.., t2.5 (where ARL $=200$ and $r=0.5)$ can be summarized as follow:

- The upper control limit is 41.0. Therefore, we expect the MEWMA statistics to fall below 41.0.

- Test results indicate that 274 points beyond the control limits.

- Test results indicate that the process is in-control for 458 points and out-of control for 274 points. Then the out-of-control rate $37.43 \%$ and the in-control rate $62.57 \%$. 


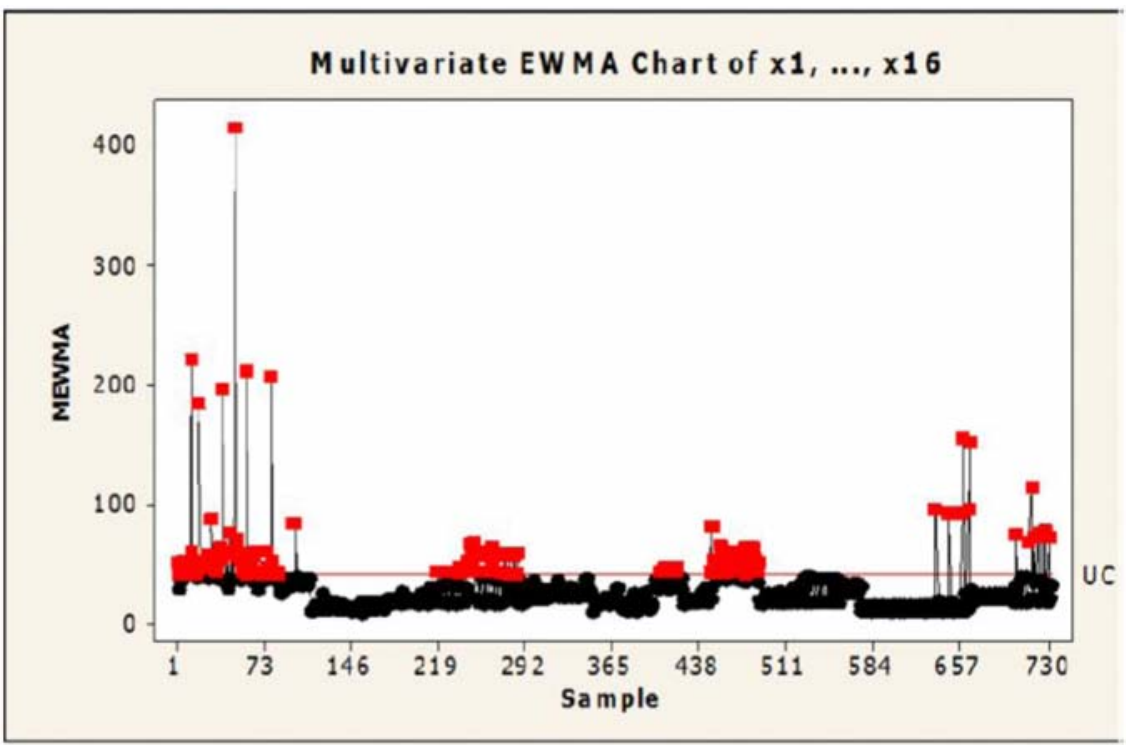

Figure 4. MEWMA chart of $\mathrm{X} 1, \ldots, \mathrm{X} 16$ with $\mathrm{ARL}=200, r=0.7$.

MEWMA chart of X1, .., X16 and t1.1, ., t2.5 (where ARL $=200$ and $r=0.7)$ can be summarized as follows:

- The upper control limit is 41.5. Therefore, we expect the MEWMA statistics to fall below 41.5.

- Test results indicate that 140 points beyond the control limits.

- Test results indicate that the process is in-control for 592 points and out-of control for 140 points. Then the out-of-control rate $19.13 \%$ and the in-control rate $80.87 \%$. 


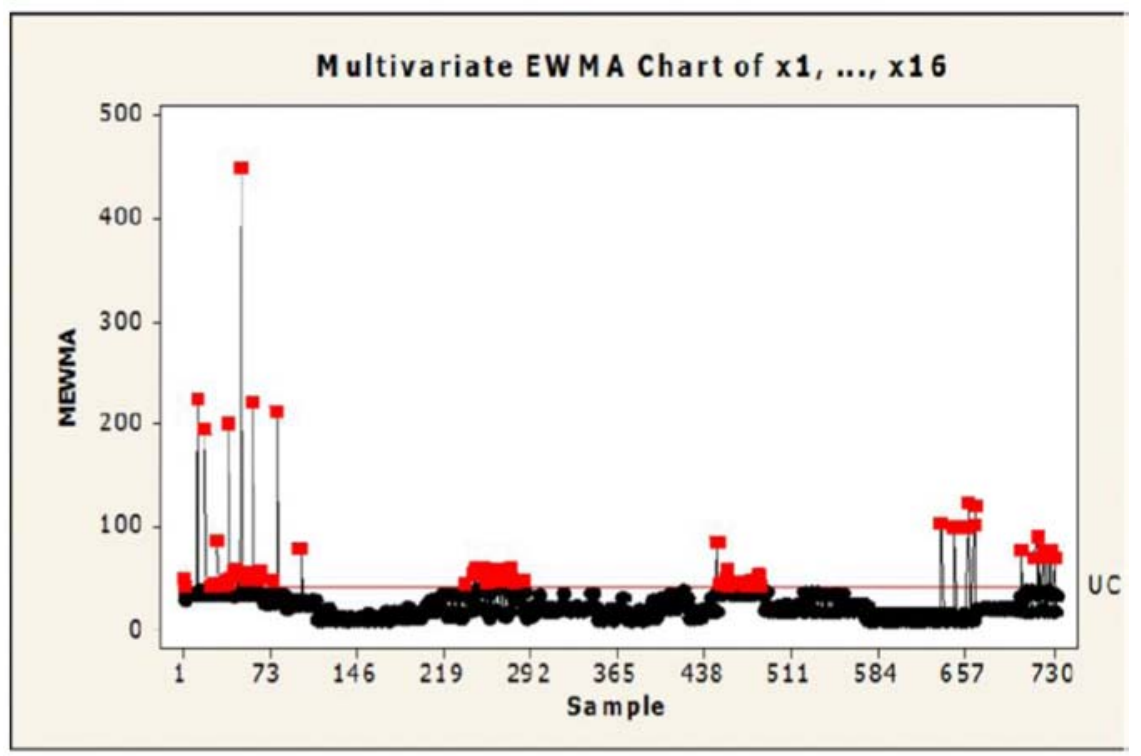

Figure 5. MEWMA chart of $\mathrm{X} 1, \ldots, \mathrm{X} 16$ with $\mathrm{ARL}=200, r=0.9$.

MEWMA chart of $\mathrm{X} 1, \ldots, \mathrm{X} 16$ and $\mathrm{t} 1.1, \ldots, \mathrm{t} 2.5$ (where $\mathrm{ARL}=200$ and $r=0.9)$ can be summarized as follows:

- The upper control limit is 42.0. Therefore, we expect the MEWMA statistics to fall below 42.0 .

- Test results indicate that 83 points beyond the control limits.

- Test results indicate that the process is in-control for 649 points and out-of control for 83 points. Then the out-of-control rate $11.34 \%$ and the in-control rate $88.66 \%$. 


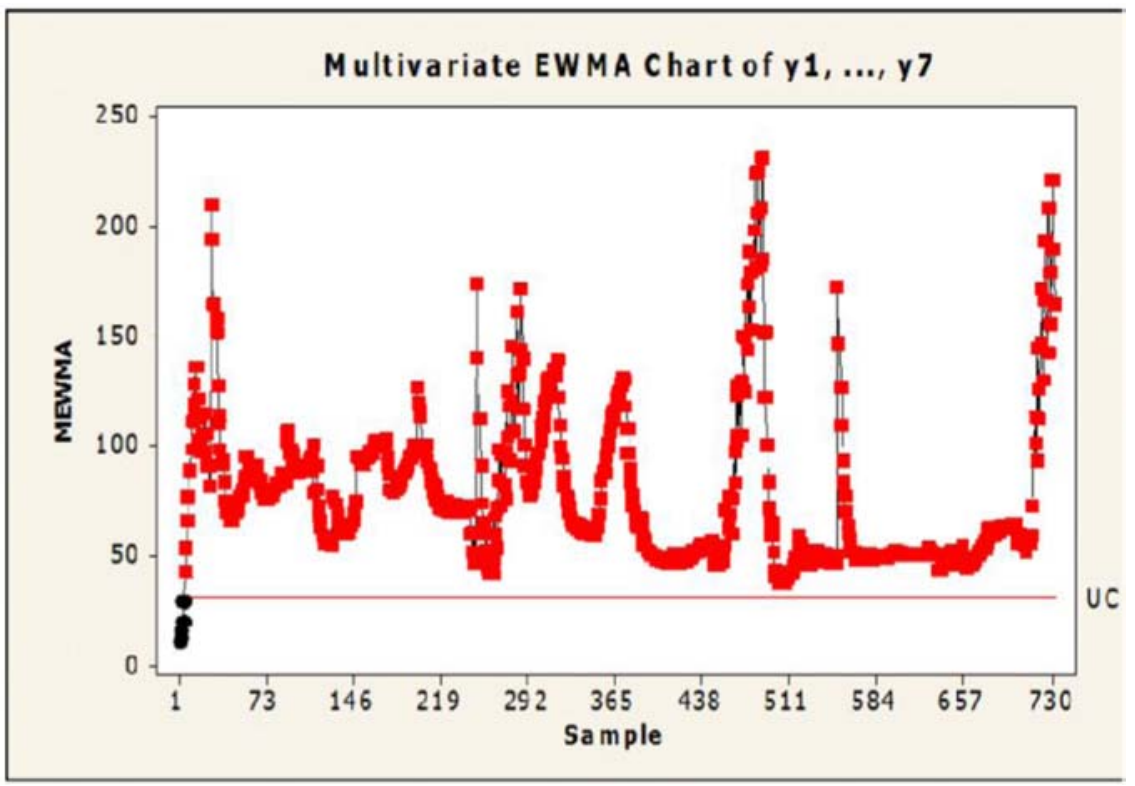

Figure 6. MEWMA chart of $\mathrm{y} 1, \ldots, \mathrm{y} 7$ with $\mathrm{ARL}=200, r=0.1$.

MEWMA chart of $\mathrm{y} 1, \ldots, \mathrm{y} 7$ and $\mathrm{t} 3.1, \ldots, \mathrm{t} 4.5$ (where ARL $=200$ and $r=0.1)$ can be summarized as follows:

- The upper control limit is 30.4. Therefore, we expect the MEWMA statistics to fall below 30.4 .

- Test results indicate that all points beyond the control limits except points 1, 2, 3, 4, and 5 fall below the upper control limit.

- Test results indicate that the process is in-control for five points and out-of control for 727 points. Then the out-of-control rate $99.32 \%$ and the in-control rate $0.68 \%$. 


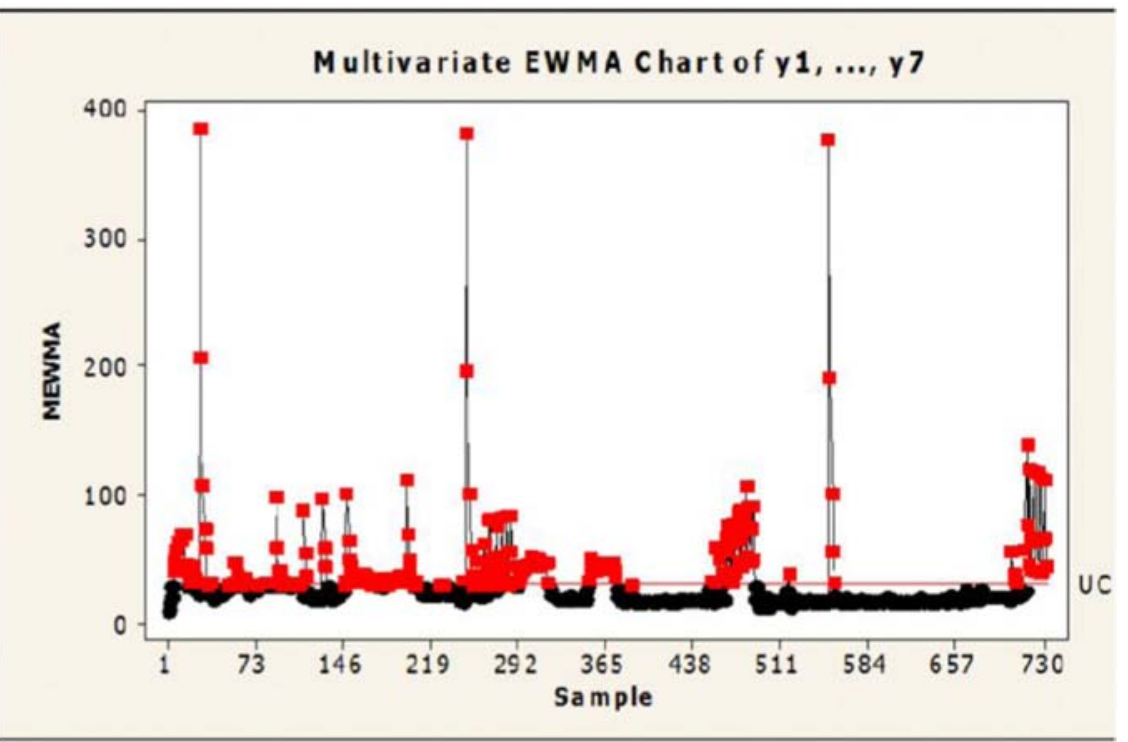

Figure 7. MEWMA chart of $\mathrm{y} 1, \ldots, \mathrm{y} 7$ with $\mathrm{ARL}=200, r=0.3$.

MEWMA chart of $\mathrm{y} 1, \ldots, \mathrm{y} 7$ and $\mathrm{t} 3.1, \ldots, \mathrm{t} 4.5$ (where $\mathrm{ARL}=200$ and $r=0.3)$ can be summarized as follows:

- The upper control limit is 30.9. Therefore, we expect the MEWMA statistics to fall below 30.9 .

- Test results indicate that 256 points beyond the control limits.

- Test results indicate that the process is in-control for 476 points and out-of control for 256 points. Then the out-of-control rate $34.97 \%$ and the in-control rate $65.03 \%$. 


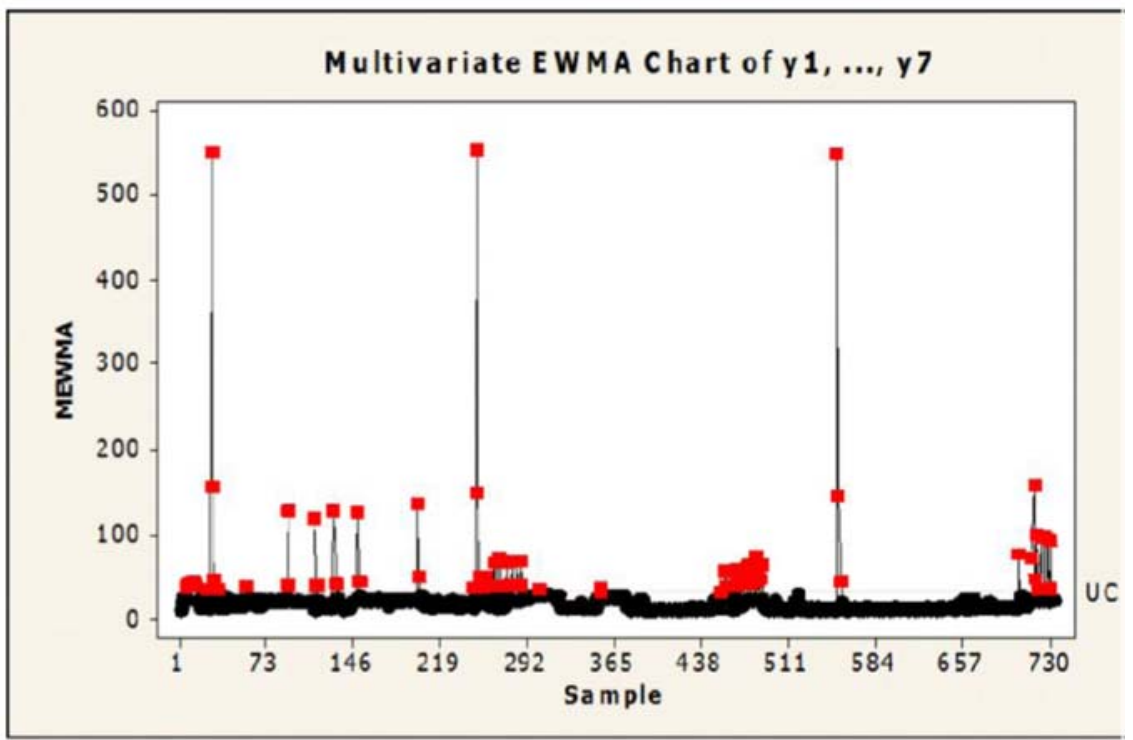

Figure 8. MEWMA chart of $\mathrm{y} 1, \ldots, \mathrm{y} 7$ with $\mathrm{ARL}=200, r=0.5$.

MEWMA chart of $\mathrm{y} 1, \ldots, \mathrm{y} 7$ and $\mathrm{t} 3.1, \ldots, \mathrm{t} 4.5$ (where ARL $=200$ and $r=0.5)$ can be summarized as follows:

- The upper control limit is 31.4. Therefore, we expect the MEWMA statistics to fall below 31.4 .

- Test results indicate that 83 points beyond the control limits.

- Test results indicate that the process is in-control for 649 points and out-of control for 83 points. Then the out-of-control rate $11.34 \%$ and the in-control rate $88.66 \%$. 


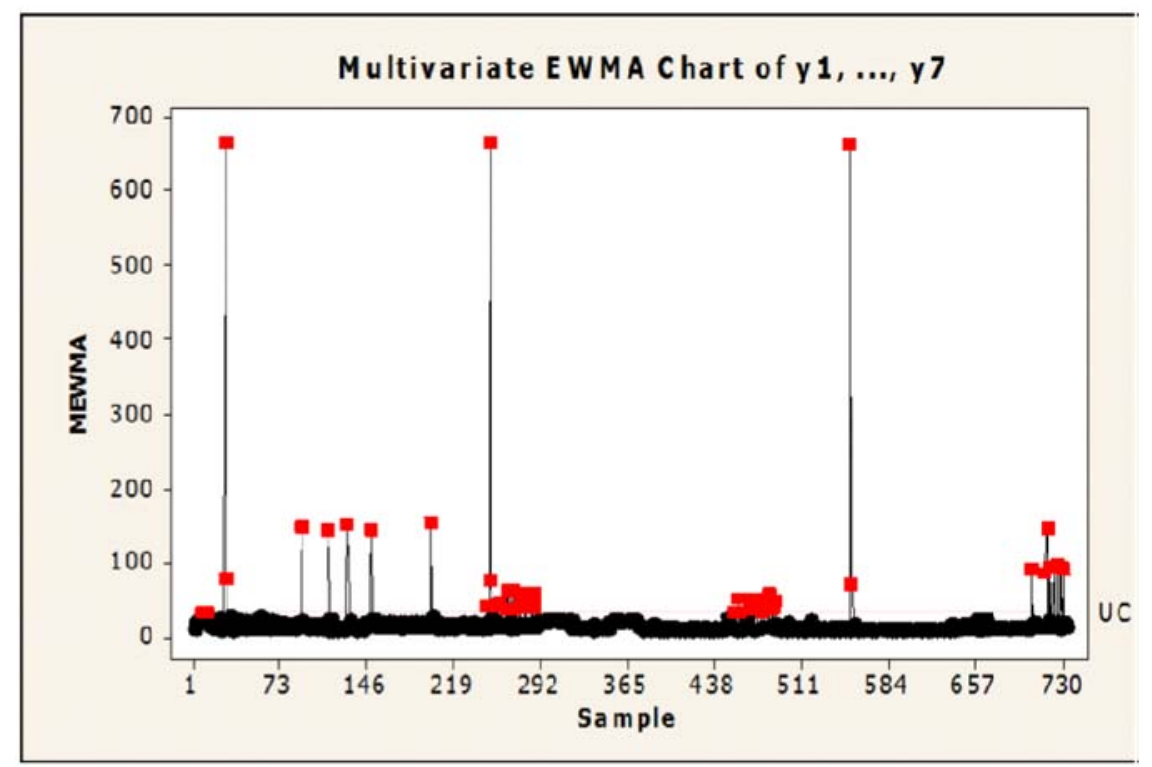

Figure 9. MEWMA chart of $\mathrm{y} 1, \ldots, \mathrm{y} 7$ with $\mathrm{ARL}=200, r=0.7$.

MEWMA chart of $y 1, \ldots, y 7$ and $\mathrm{t} 3.1, \ldots, \mathrm{t} 4.5$ (where ARL $=200$ and $r=0.7)$ can be summarized as follows:

- The upper control limit is 31.9. Therefore, we expect the MEWMA statistics to fall below 31.9.

- Test results indicate that 58 points beyond the control limits.

- Test results indicate that the process is in-control for 674 points and out-of control for 58 points. Then the out-of-control rate $7.92 \%$ and the in-control rate $92.08 \%$. 


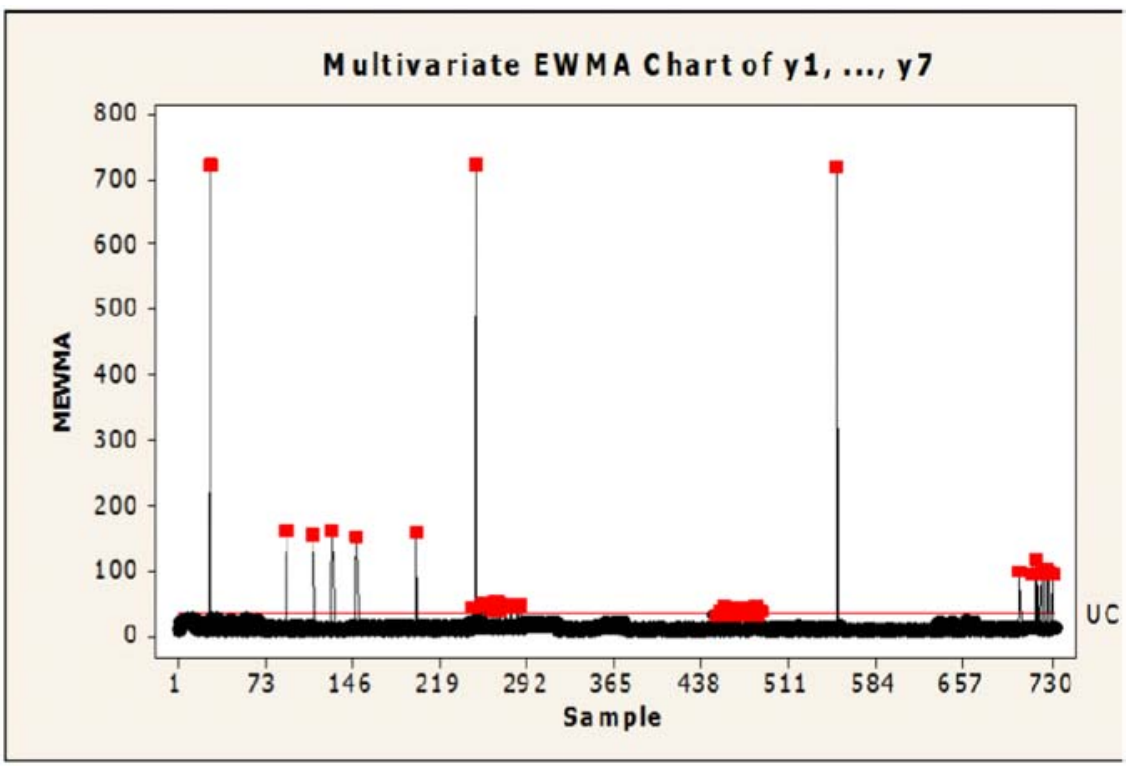

Figure 10. MEWMA chart of $\mathrm{y} 1, \ldots, \mathrm{y} 7$ with $\mathrm{ARL}=200, r=0.9$.

MEWMA chart of y1, .., y7 and t3.1, .., t4.5 (where ARL $=200$ and $r=0.9)$ can be summarized as follows:

- The upper control limit is 32.3. Therefore, we expect the MEWMA statistics to fall below 32.3 .

- Test results indicate that 54 points beyond the control limits.

- Test results indicate that the process is in-control for 678 points and out-of control for 54 points. Then the out-of-control rate $7.38 \%$ and the in-control rate $92.62 \%$. 


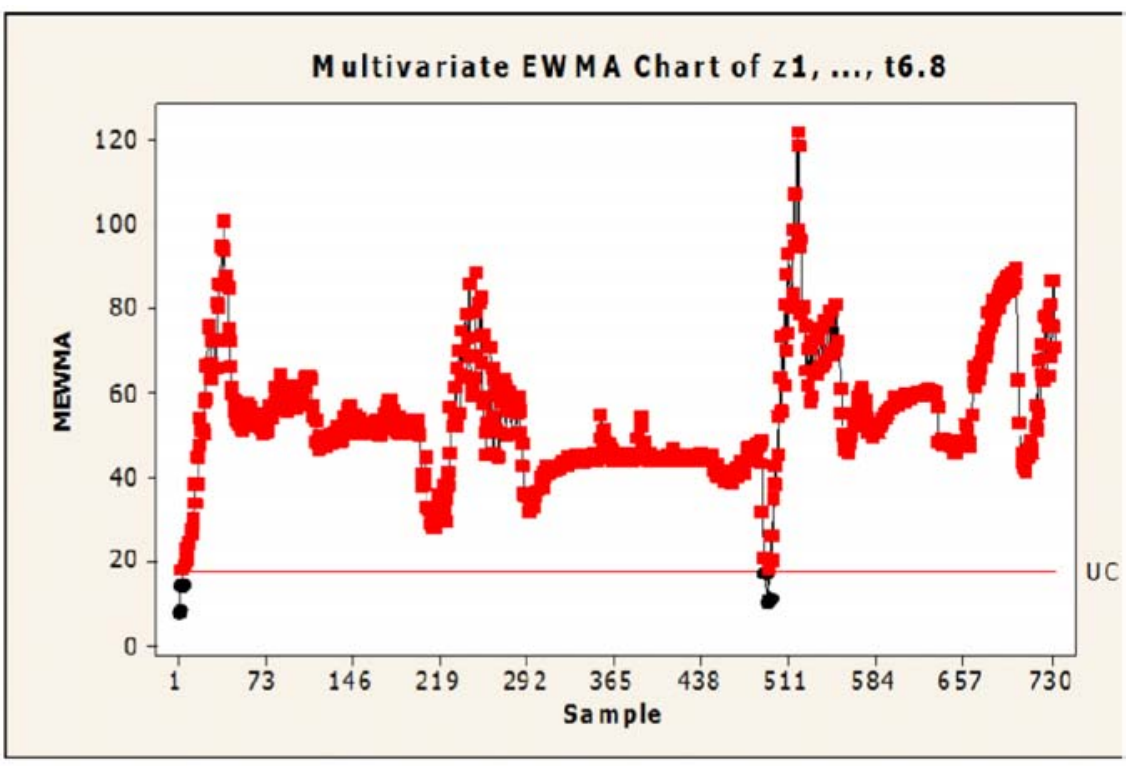

Figure 11. MEWMA chart of $\mathrm{Z} 1, \ldots$, t6.8 with $\mathrm{ARL}=200, r=0.1$.

MEWMA chart of Z1, .., Z4 and t6.1,.., t6.8 (where ARL = 200 and $r=0.1)$ can be summarized as follows:

- The upper control limit is 17.6. Therefore, we expect the MEWMA statistics to fall below 17.6.

- Test results indicate that all points beyond the control limits except points 1, 2, 3, and 4 fall below the upper control limit.

- Test results indicate that the process is in-control for four points and out-of control for 728 points. Then the out-of- control rate $99.45 \%$ and the in-control rate $0.55 \%$. 


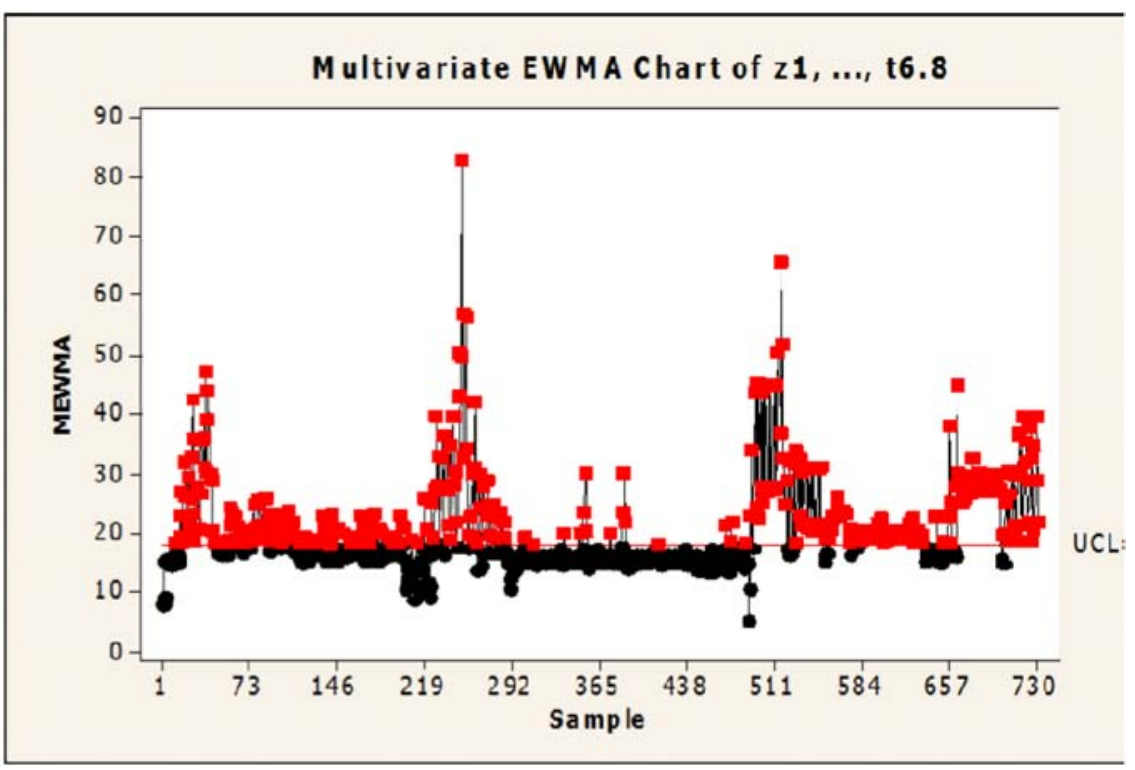

Figure 12. MEWMA chart of $\mathrm{Z} 1, \ldots$, t6.8 with $\mathrm{ARL}=200, r=0.3$.

MEWMA chart of $\mathrm{Z} 1, \ldots, \mathrm{Z} 4$ and $\mathrm{t} 6.1, \ldots, \mathrm{t} 6.8$ (where $\mathrm{ARL}=200$ and $r=0.3)$ can be summarized as follows:

- The upper control limit is 18.05. Therefore, we expect the MEWMA statistics to fall below 18.05 .

- Test results indicate 401 points through beyond the control limits.

- Test results indicate that the process is in-control for 331 points and out-of control for 401 points. Then the out-of-control rate $54.78 \%$ and the in-control rate $45.22 \%$. 


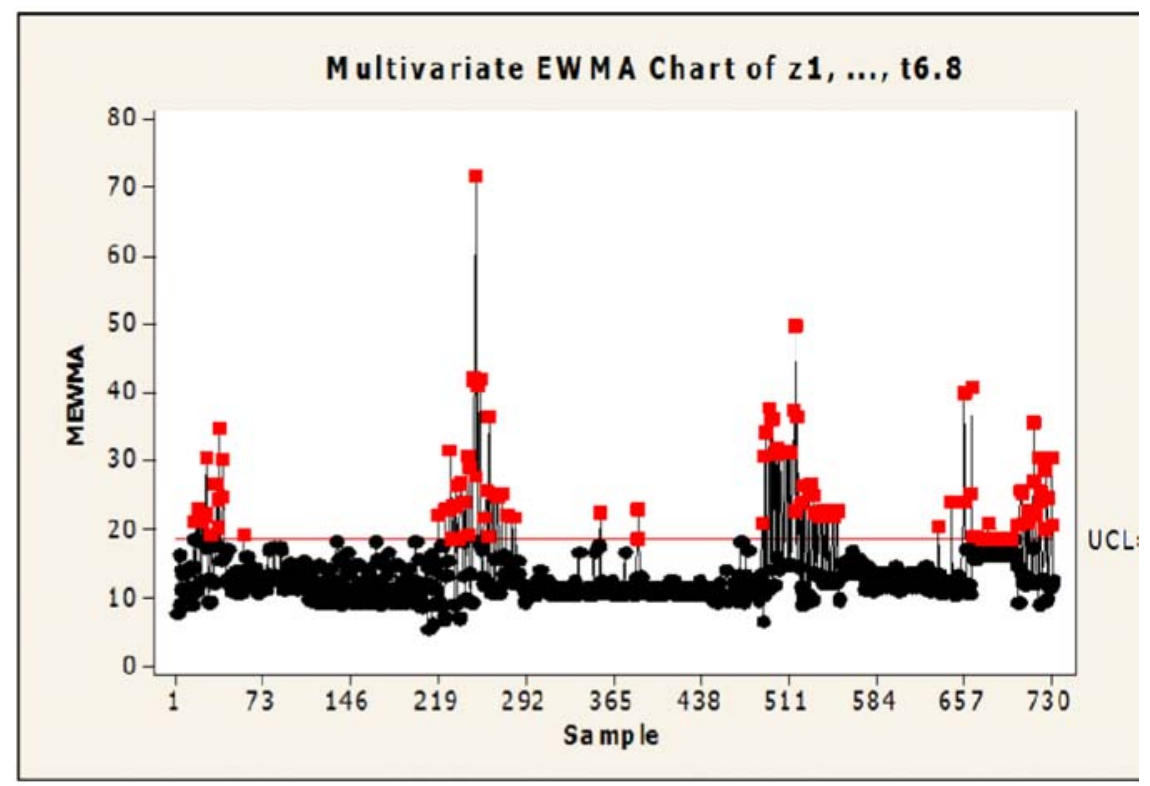

Figure 13. MEWMA chart of $\mathrm{Z1}, \ldots$, t6.8 with $\mathrm{ARL}=200, r=0.5$.

MEWMA chart of $\mathrm{Z} 1, \ldots, \mathrm{Z} 4$ and $\mathrm{t} 6.1, \ldots, \mathrm{t} 6.8$ (where $\mathrm{ARL}=200$ and $r=0.5)$ can be summarized as follows:

- The upper control limit is 18.54. Therefore, we expect the MEWMA statistics to fall below 18.54 .

- Test results indicate 115 points through beyond the control limits.

- Test results indicate that the process is in-control for 617 points and out-of control for 115 points. Then the out-of-control rate $15.7 \%$ and the in-control rate $84.3 \%$. 


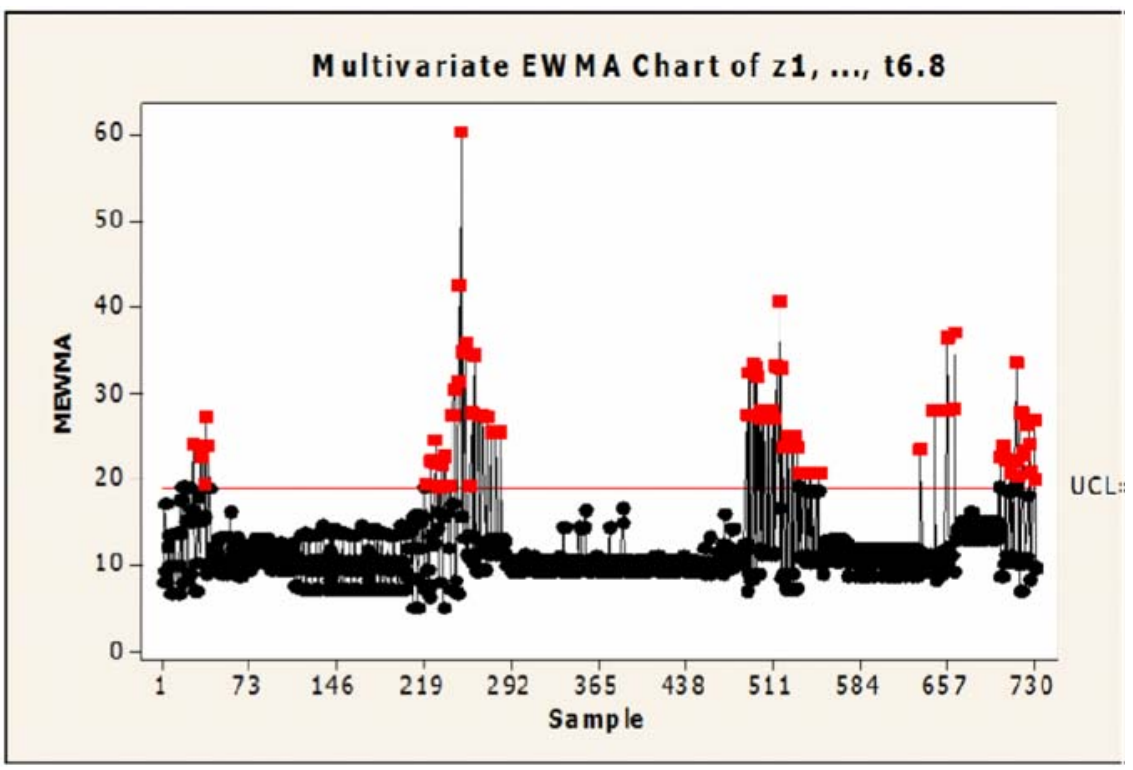

Figure 14. MEWMA chart of $\mathrm{Z} 1, \ldots, \mathrm{t} 6.8$ with $\mathrm{ARL}=200, r=0.7$.

MEWMA chart of $\mathrm{Z} 1, \ldots, \mathrm{Z} 4$ and $\mathrm{t} 6.1, \ldots, \mathrm{t} 6.8$ (where ARL $=200$ and $r=0.7)$ can be summarized as follows:

- The upper control limit is 19.03. Therefore, we expect the MEWMA statistics to fall below 19.03 .

- Test results indicate 78 points through beyond the control limits

- Test results indicate that the process is in- control for 654 points and out-of control for 78 points. Then the out-of-control rate $10.66 \%$ and the in-control rate $89.34 \%$. 


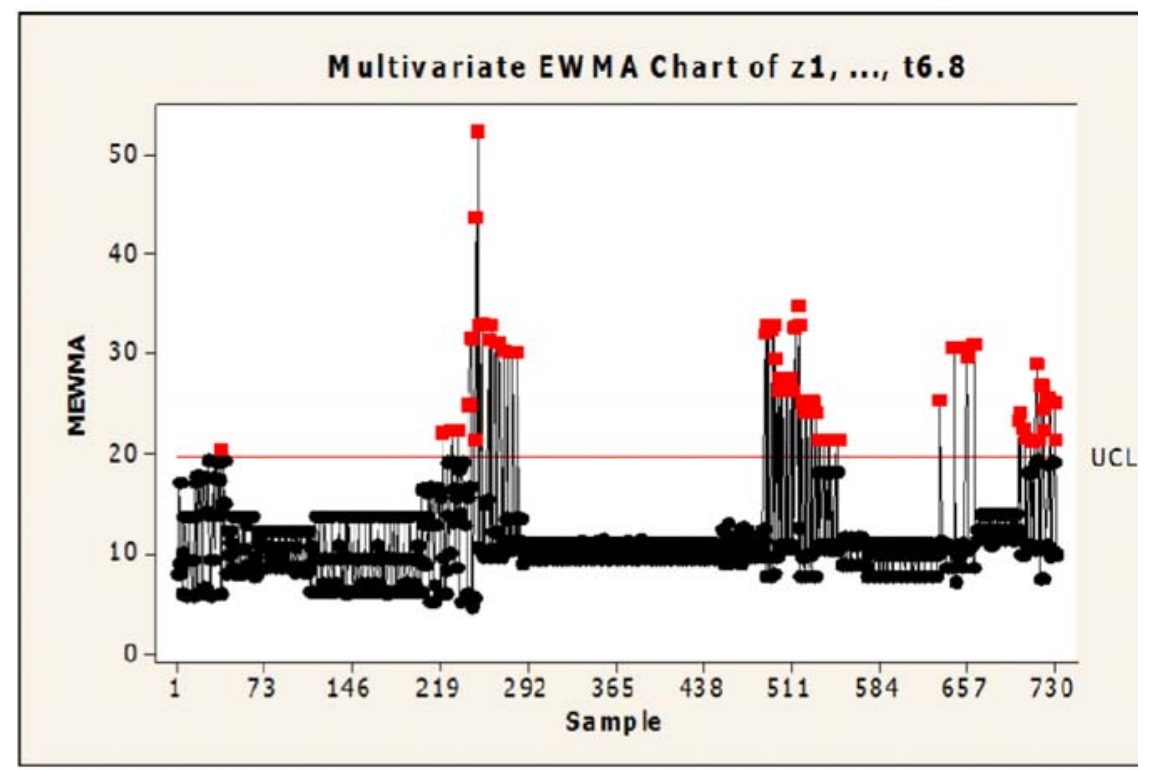

Figure 15. MEWMA chart of $\mathrm{Z1}, \ldots, \mathrm{t} 6.8$ with $\mathrm{ARL}=200, r=0.9$.

MEWMA chart of $\mathrm{Z} 1, \ldots, \mathrm{Z} 4$ and $\mathrm{t} 6.1, \ldots, \mathrm{t} 6.8$ (where ARL $=200$ and $r=0.9)$ can be summarized as follows:

- The upper control limit is 19.52. Therefore, we expect the MEWMA statistics to fall below 19.52 .

- Test results indicate 67 points through beyond the control limits.

- Test result indicate that the process is in-control for 665 points and out-of control for 67 points. Then the out-of- control rate $9.15 \%$ and the in-control rate $90.85 \%$. 
Table 1. Summarize MEWMA charts

\begin{tabular}{|c|c|c|c|c|c|c|c|c|c|c|c|c|c|c|c|}
\hline & \multicolumn{3}{|c|}{$\mathrm{ARL}=200, r=0.1$} & \multicolumn{3}{|c|}{$\mathrm{ARL}=200, r=0.3$} & \multicolumn{3}{|c|}{$\mathrm{ARL}=200, r=0.5$} & \multicolumn{3}{|c|}{$\mathrm{ARL}=200, r=0.7$} & \multicolumn{3}{|c|}{$\mathrm{ARL}=200, r=0.9$} \\
\hline & UCL & $\begin{array}{l}\text { Out-of- } \\
\text { control } \\
\text { rate }\end{array}$ & \begin{tabular}{|c|} 
In- \\
control \\
rate
\end{tabular} & UCL & $\begin{array}{c}\text { Out-of- } \\
\text { control } \\
\text { rate }\end{array}$ & $\begin{array}{c}\text { In- } \\
\text { control } \\
\text { rate }\end{array}$ & UCL & $\begin{array}{c}\text { Out-of- } \\
\text { control } \\
\text { rate }\end{array}$ & $\begin{array}{c}\text { In- } \\
\text { control } \\
\text { rate }\end{array}$ & UCL & $\begin{array}{c}\text { Out-of- } \\
\text { control } \\
\text { rate }\end{array}$ & $\begin{array}{c}\text { In- } \\
\text { control } \\
\text { rate }\end{array}$ & UCL & $\begin{array}{c}\text { Out-of- } \\
\text { control } \\
\text { rate }\end{array}$ & $\begin{array}{c}\text { In- } \\
\text { control } \\
\text { rate }\end{array}$ \\
\hline $\begin{array}{l}\text { MEWMA for } \\
\mathrm{X} 1, \ldots, \mathrm{X} 16\end{array}$ & 40.00 & $99.73 \%$ & $0.27 \%$ & 40.50 & $67.08 \%$ & $32.92 \%$ & 41.00 & $37.43 \%$ & $62.57 \%$ & 41.50 & $19.13 \%$ & $80.87 \%$ & 42.00 & $11.34 \%$ & $88.66 \%$ \\
\hline $\begin{array}{c}\text { MEWMA for } \\
\mathrm{y} 1, \ldots, \mathrm{y} 7\end{array}$ & 30.40 & $99.32 \%$ & $0.68 \%$ & 30.9 & $34.97 \%$ & $65.03 \%$ & 31.4 & $11.34 \%$ & $88.66 \%$ & 31.90 & $7.92 \%$ & $92.08 \%$ & 32.30 & $7.38 \%$ & $92.62 \%$ \\
\hline $\begin{array}{l}\text { MEWMA for } \\
\mathrm{Z} 1, \ldots, \mathrm{t} 6.8\end{array}$ & 17.60 & $99.45 \%$ & $0.55 \%$ & 18.05 & $54.78 \%$ & $45.22 \%$ & 18.54 & $15.70 \%$ & $84.30 \%$ & 19.03 & $10.66 \%$ & $89.34 \%$ & 19.52 & $9.15 \%$ & $90.85 \%$ \\
\hline
\end{tabular}




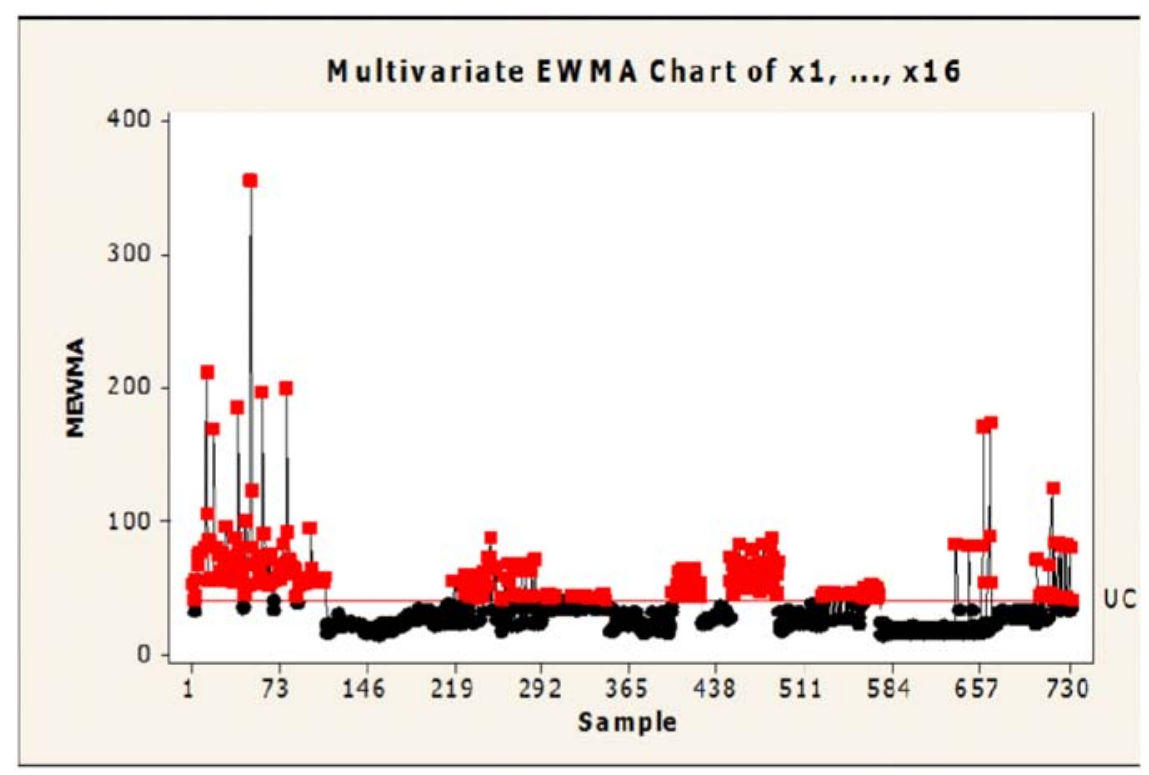

Figure 16. MEWMA chart of $\mathrm{X} 1, \ldots, \mathrm{X} 16$ with $\mathrm{ARL}=100, r=0.5$.

MEWMA chart of X1, ., X16 and t1.1,.., t2.5 (where ARL = 100 and $r=05)$ can be summarized as follows:

- The upper control limit is 40.2. Therefore, we expect the MEWMA statistics to fall below 40.2 .

- Test results indicate that 278 points beyond the control limits.

- Test results indicate that the process is in-control for 454 points and out-of control for 278 points. Then the out-of-control rate $37.98 \%$ and the in-control rate $62.02 \%$. 


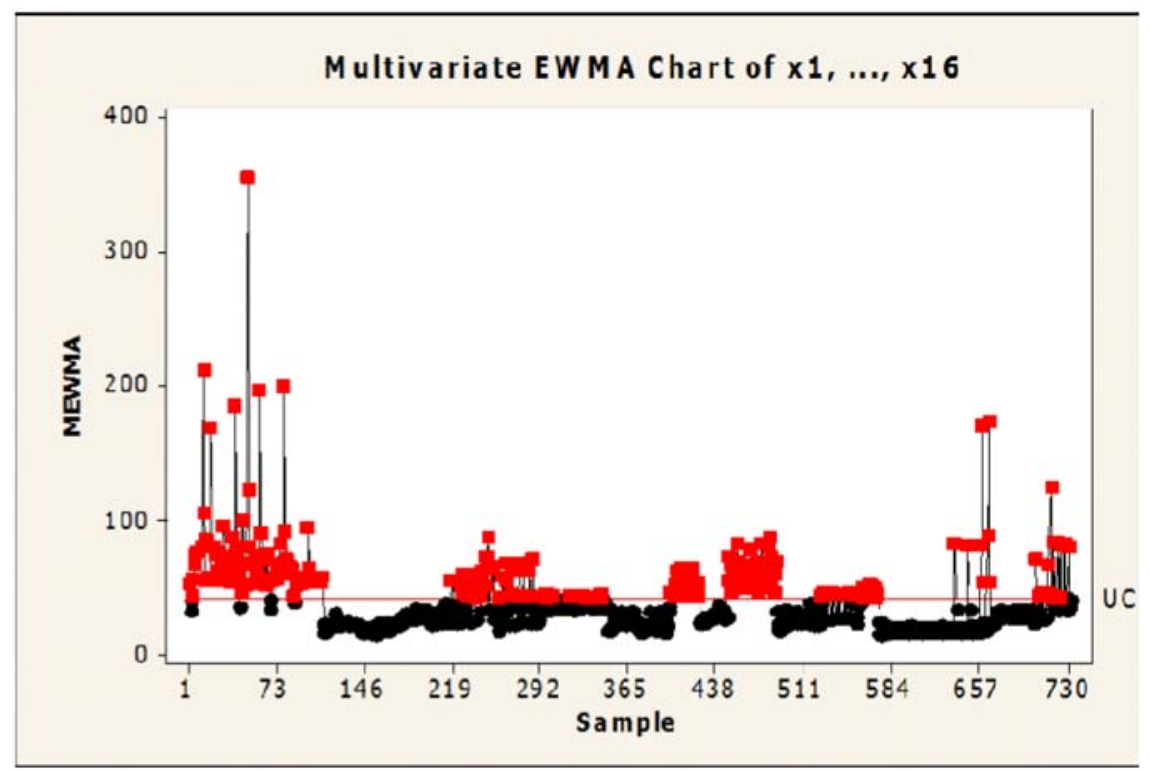

Figure 17. MEWMA chart of $\mathrm{X} 1, \ldots, \mathrm{X} 16$ with $\mathrm{ARL}=300, r=0.5$.

MEWMA chart of $\mathrm{X} 1, \ldots, \mathrm{X} 16$ and $\mathrm{t} 1.1, \ldots, \mathrm{t} 2.5$ (where $\mathrm{ARL}=300$ and $r=05)$ can be summarized as follows:

- The upper control limit is 41.4. Therefore, we expect the MEWMA statistics to fall below 41.4 .

- Test results indicate that 271 points beyond the control limits.

- Test results indicate that the process is in-control for 461 points and out-of control for 271 points. Then the out-of-control rate $38.02 \%$ and the in-control rate $62.98 \%$. 


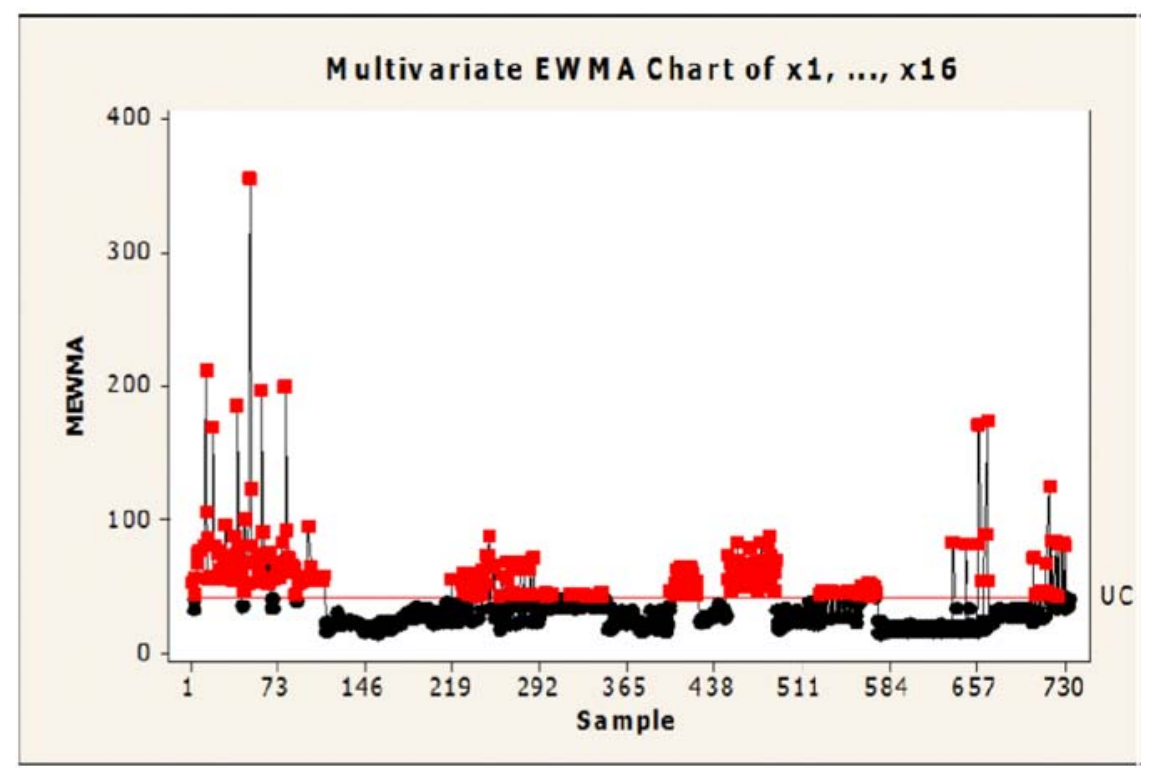

Figure 18. MEWMA chart of $\mathrm{X} 1, \ldots, \mathrm{X} 16$ with $\mathrm{ARL}=400, r=0.5$.

MEWMA chart of $\mathrm{X} 1, \ldots, \mathrm{X} 16$ and $\mathrm{t} 1.1, \ldots, \mathrm{t} 2.5$ (where $\mathrm{ARL}=400$ and $r=05)$ can be summarized as follows:

- The upper control limit is 41.7. Therefore, we expect the MEWMA statistics to fall below 41.7 .

- Test results indicate that 268 points beyond the control limits.

- Test results indicate that the process is in-control for 464 points and out-of control for 268 points. Then the out-of-control rate $36.61 \%$ and the in-control rate $63.39 \%$. 


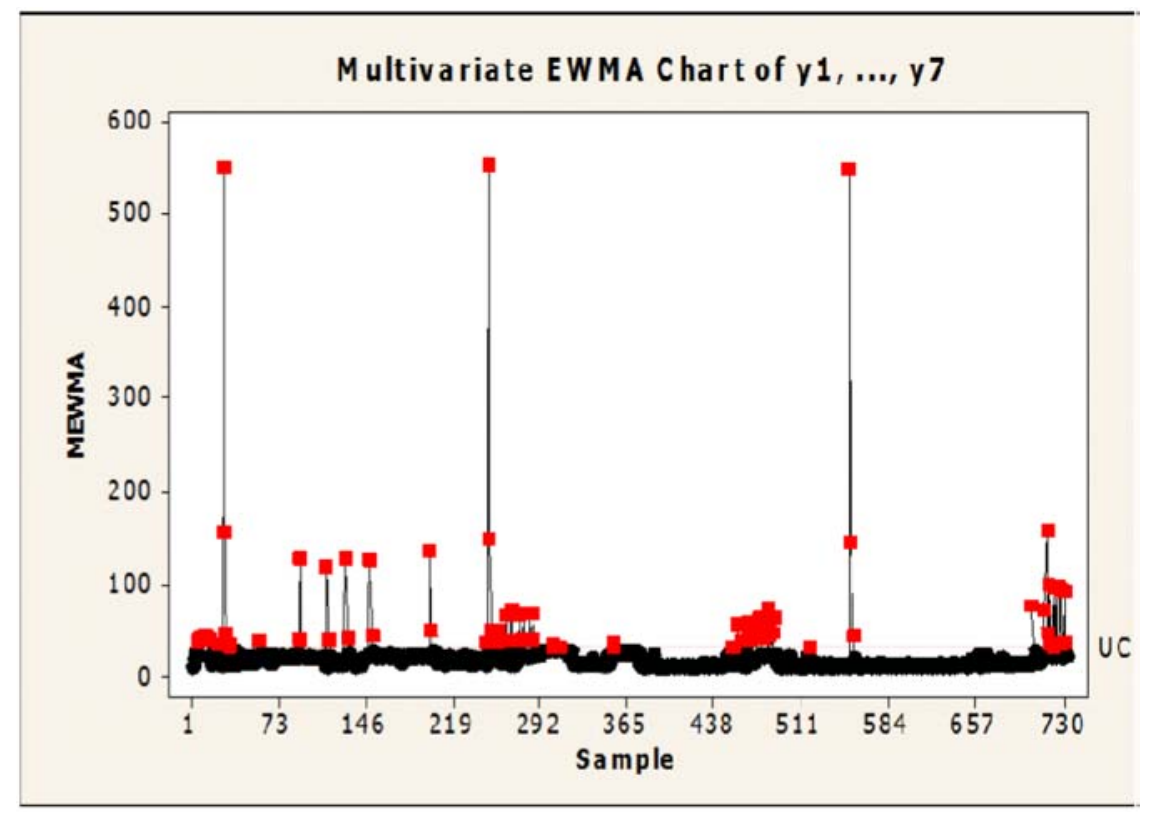

Figure 19. MEWMA chart of $\mathrm{y} 1, \ldots, \mathrm{y} 7$ with $\mathrm{ARL}=100, r=0.5$.

MEWMA chart of $\mathrm{y} 1, \ldots, \mathrm{y} 7$ and $\mathrm{t} 3.1, \ldots, \mathrm{t} 4.5$ (where $\mathrm{ARL}=100$ and $r=0.5$ ) can be summarized as follows:

- The upper control limit is 30.6. Therefore, we expect the MEWMA statistics to fall below 30.6.

- Test results indicate that 89 points beyond the control limits.

- Test results indicate that the process is in-control for 634 points and out-of control for 89 points. Then the out-of-control rate $12.16 \%$ and the in-control rate $87.84 \%$. 


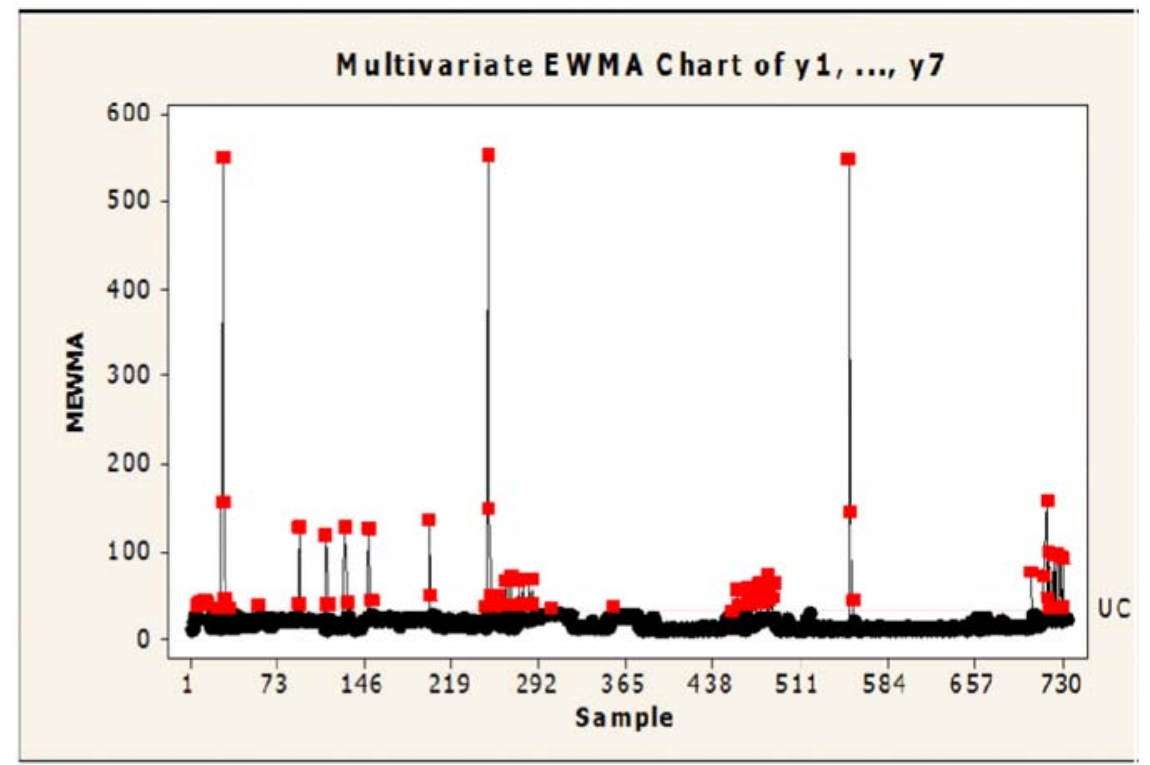

Figure 20. MEWMA chart of $\mathrm{y} 1, \ldots, \mathrm{y} 7$ with $\mathrm{ARL}=300, r=0.5$.

MEWMA chart of $\mathrm{y} 1, \ldots, \mathrm{y} 7$ and $\mathrm{t} 3.1, \ldots, \mathrm{t} 4.5$ (where $\mathrm{ARL}=300$ and $r=0.5)$ can be summarized as follows:

- The upper control limit is 31.8. Therefore, we expect the MEWMA statistics to fall below 31.8 .

- Test results indicate that 82 points beyond the control limits.

- Test results indicate that the process is in-control for 650 points and out-of control for 82 points. Then the out-of-control rate $11.20 \%$ and the in-control rate $88.80 \%$. 


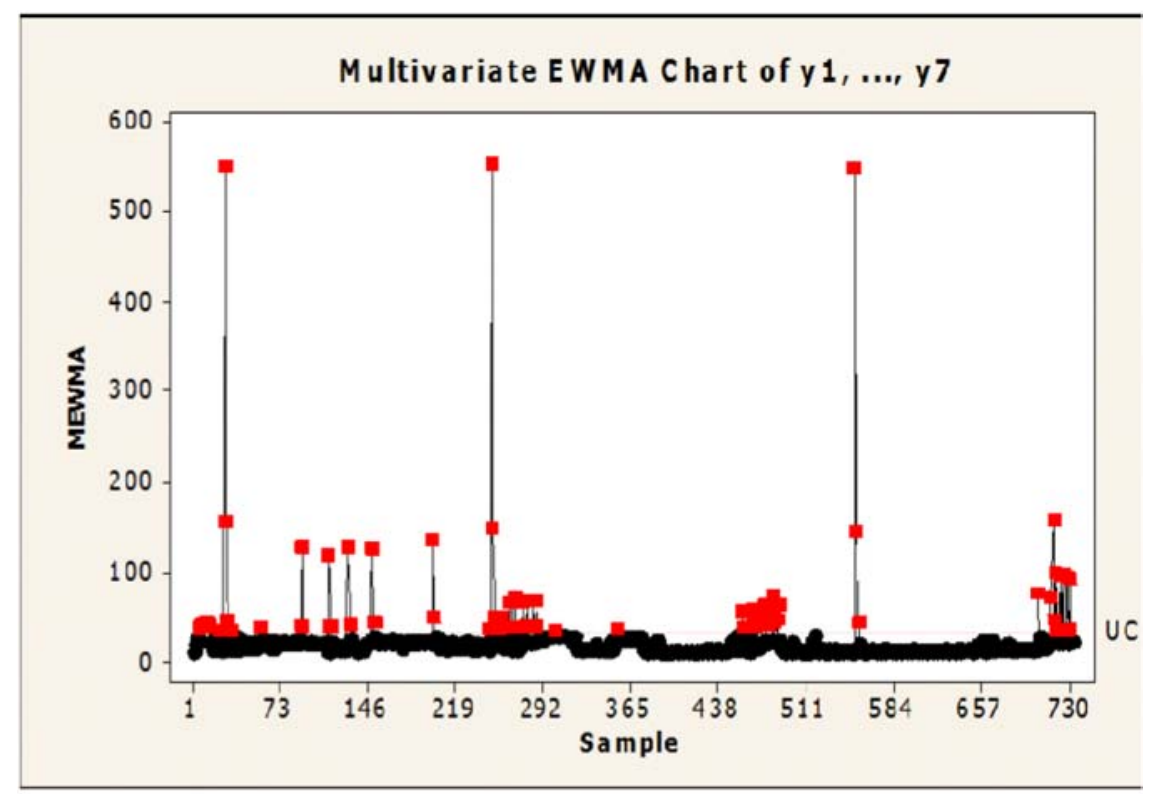

Figure 21. MEWMA chart of $\mathrm{y} 1, \ldots, \mathrm{y} 7$ with $\mathrm{ARL}=400, r=0.5$.

MEWMA chart of $\mathrm{y} 1, \ldots, \mathrm{y} 7$ and $\mathrm{t} 3.1, \ldots, \mathrm{t} 4.5$ (where ARL $=400$ and $r=0.5$ ) can be summarized as follows:

- The upper control limit is 32.1. Therefore, we expect the MEWMA statistics to fall below 32.1 .

- Test results indicate that 81 points beyond the control limits.

- Test results indicate that the process is in-control for 651 points and out-of control for 81 points. Then the out-of-control rate $11.07 \%$ and the in-control rate $88.93 \%$. 


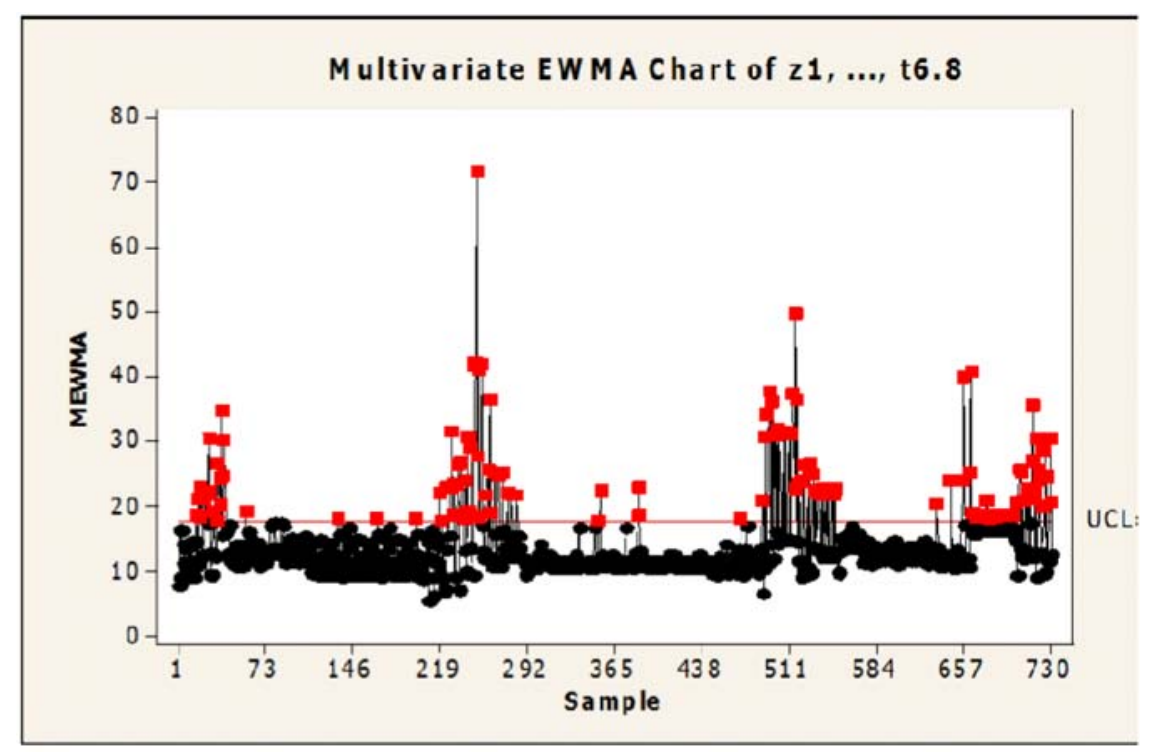

Figure 22. MEWMA chart of $\mathrm{Z} 1, \ldots, \mathrm{t} 6.8$ with $\mathrm{ARL}=100, r=0.5$.

MEWMA chart of $\mathrm{Z} 1, \ldots, \mathrm{Z} 4$ and $\mathrm{t} 6.1, \ldots, \mathrm{t} 6.8$ (where $\mathrm{ARL}=100$ and $r=0.5)$ can be summarized as follows:

- The upper control limit is 17.78. Therefore, we expect the MEWMA statistics to fall below 17.78 .

- Test results indicate 135 points through beyond the control limits.

- Test results indicate that the process is in-control for 597 points and out-of control for 135 points. Then the out-of-control rate $18.44 \%$ and the in-control rate $81.56 \%$. 


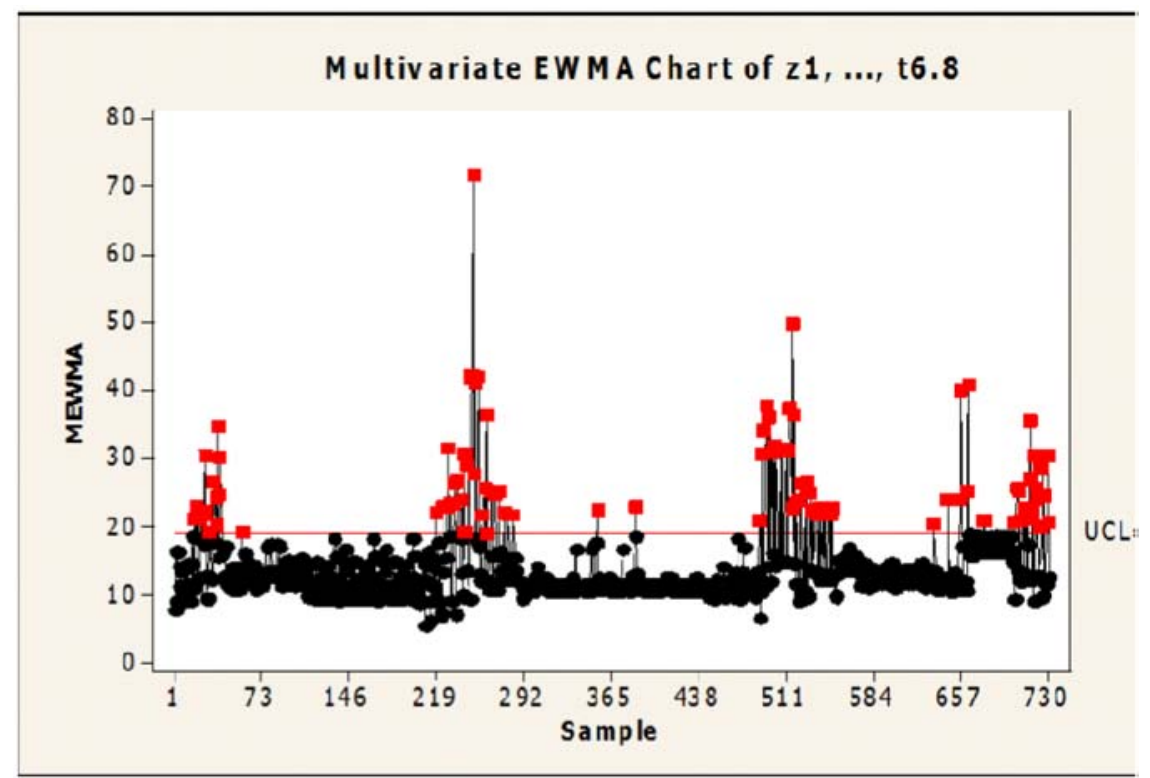

Figure 23. MEWMA chart of $\mathrm{Z1}, \ldots$, t6.8 with $\mathrm{ARL}=300, r=0.5$.

MEWMA chart of $\mathrm{Z} 1, \ldots, \mathrm{Z} 4$ and $\mathrm{t} 6.1, \ldots, \mathrm{t} 6.8$ (where $\mathrm{ARL}=300$ and $r=0.5)$ can be summarized as follows:

- The upper control limit is 18.99. Therefore, we expect the MEWMA statistics to fall below 18.99 .

- Test results indicate 102 points through beyond the control limits.

- Test results indicate that the process is in-control for 630 points and out-of control for 102 points. Then the out-of-control rate $13.93 \%$ and the in-control rate $86.07 \%$. 


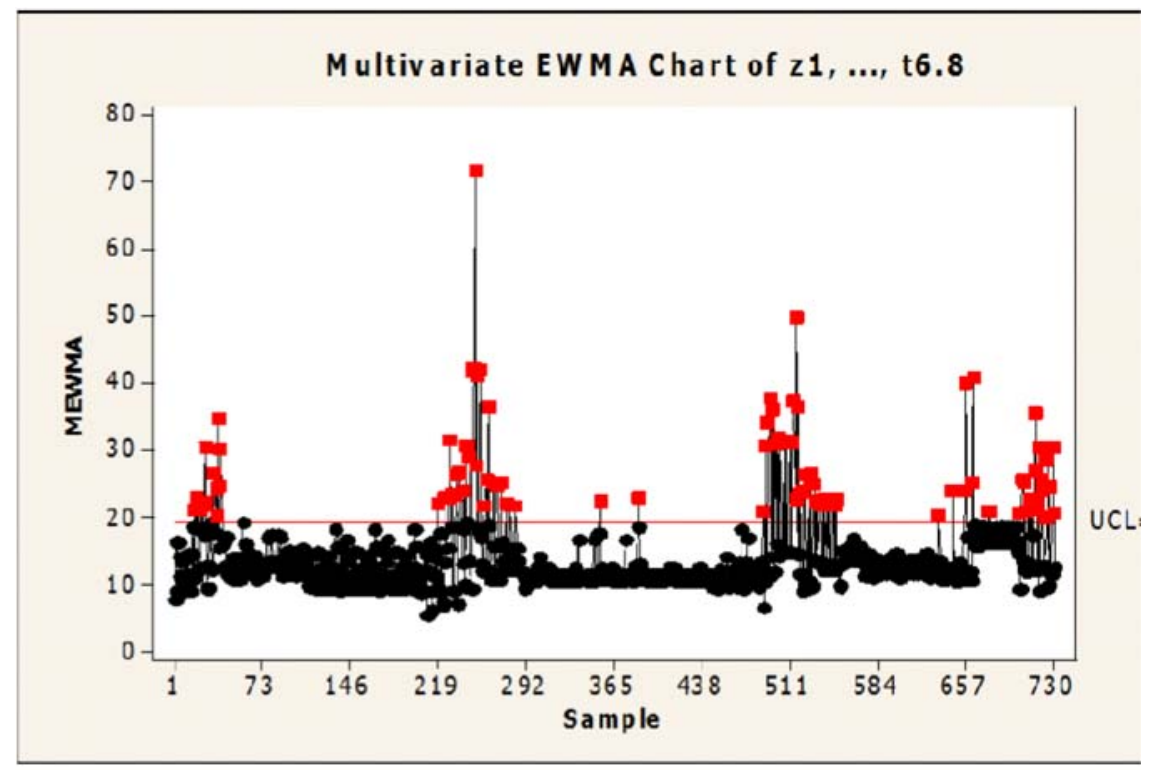

Figure 24. MEWMA chart of $\mathrm{Z1}, \ldots$, t6.8 with $\mathrm{ARL}=400, r=0.5$.

MEWMA chart of $\mathrm{Z} 1, \ldots, \mathrm{Z} 4$ and $\mathrm{t} 6.1, \ldots, \mathrm{t} 6.8$ (where $\mathrm{ARL}=400$ and $r=0.5)$ can be summarized as follows:

- The upper control limit is 19.31. Therefore, we expect the MEWMA statistics to fall below 19.31 .

- Test results indicate 98 points through beyond the control limits.

- Test results indicate that the process is in-control for 634 points and out-of control for 98 points. Then the out-of-control rate $13.39 \%$ and the in-control rate $86.61 \%$.

- Test results indicate that for the same $\mathrm{ARL}=200$ the out of control rate decreased by increasing the value of $r$

- Test results indicate that UCL increased by increasing the value of $r$. 
- We note that for the same value of $r$ the out-of control decreased by increasing the value of ARL but with small rate.

- Finally, we note that we use small value of $r$ to determine small shift in the process mean and use large value of $r$ to determine large shift in the process mean. 
Table 2. Summarize MEWMA charts

\begin{tabular}{|c|c|c|c|c|c|c|c|c|c|c|c|c|}
\hline & \multicolumn{3}{|c|}{$\mathrm{ARL}=100, r=0.5$} & \multicolumn{3}{|c|}{$\mathrm{ARL}=200, r=0.5$} & \multicolumn{3}{|c|}{$\mathrm{ARL}=300, r=0.5$} & \multicolumn{3}{|c|}{$\mathrm{ARL}=400, r=0.5$} \\
\hline & UCL & $\begin{array}{c}\text { Out-of- } \\
\text { control } \\
\text { rate }\end{array}$ & $\begin{array}{l}\text { In- } \\
\text { control } \\
\text { rate }\end{array}$ & UCL & $\begin{array}{l}\text { Out-of- } \\
\text { control } \\
\text { rate }\end{array}$ & $\begin{array}{l}\text { In- } \\
\text { control } \\
\text { rate }\end{array}$ & UCL & $\begin{array}{l}\text { Out-of- } \\
\text { control } \\
\text { rate }\end{array}$ & $\begin{array}{l}\text { In- } \\
\text { control } \\
\text { rate }\end{array}$ & UCL & $\begin{array}{c}\text { Out-of- } \\
\text { control } \\
\text { rate }\end{array}$ & $\begin{array}{c}\text { In- } \\
\text { control } \\
\text { rate }\end{array}$ \\
\hline $\begin{array}{l}\text { MEWMA for } \\
\mathrm{X} 1, \ldots, \mathrm{X} 16\end{array}$ & 40.20 & $37.98 \%$ & $62.02 \%$ & 41.00 & $37.43 \%$ & $62.57 \%$ & 41.40 & $38.02 \%$ & $62.98 \%$ & 41.70 & $36.61 \%$ & $63.39 \%$ \\
\hline $\begin{array}{c}\text { MEWMA for } \\
\mathrm{y} 1, \ldots, \mathrm{y} 7\end{array}$ & 30.60 & $12.16 \%$ & $87.84 \%$ & 31.4 & $11.34 \%$ & $88.66 \%$ & 31.8 & $11.20 \%$ & $88.80 \%$ & 32.10 & $11.07 \%$ & $88.93 \%$ \\
\hline $\begin{array}{l}\text { MEWMA for } \\
\mathrm{Z} 1, \ldots, \mathrm{t} 6.8\end{array}$ & 17.78 & $18.44 \%$ & $81.56 \%$ & 18.54 & $15.70 \%$ & $84.3 \%$ & 18.99 & $13.93 \%$ & $86.07 \%$ & 19.31 & $13.39 \%$ & $86.61 \%$ \\
\hline
\end{tabular}




\subsection{Test results of application study}

It is shown that in the high pressure stage, test result of MEWMA (when $r=0.1$ and ARL $=200$ ) the out-of-control percentage $99.73 \%$ and the in-control percentage $0.27 \%$. The difference occurred in the percentage is due to the sensitivity of MEWMA of the small shifts, and the out-of-control percentage (when $r=0.3, r=0.5, r=0.7, r=0.9$ and $\mathrm{ARL}=200)$ are respectively $(67.08 \%, 37.43 \%, 19.13 \%, 11.34 \%)$ and the in-control percentage $(32.92 \%, 62.57 \%, 80.87 \%, 88.66 \%)$. It is shown that in the low-pressure stage, test results of MEWMA (when $r=0.1$ and $\mathrm{ARL}=200$ ) indicate the out-of-control percentage $99.32 \%$ and the in-control $0.68 \%$, while, in the MEWMA the out-of-control percentage (when $r=0.3$, $r=0.5, r=0.7, r=0.9$, and ARL $=200)$ respectively $(34.97 \%, 11.34 \%$, $7.92 \%, 7.38 \%)$ and the in-control percentage $(65.03 \%, 88.66 \%, 92.08 \%$, $92.62 \%)$.

It is shown that in the evaporation and prilling stage, test result in MEWMA indicates (when $r=0.1, r=0.3, r=0.5, r=0.7, r=0.9$ and $\mathrm{ARL}=200)$ the out-of-control percentage respectively $(99.45 \%, 54.78 \%$, $15.70 \%, 10.66 \%, 9.15 \%)$ and the in-control percentage $(0.55 \%, 45.22 \%$, $84.3 \%, 89.34 \%, 90.85 \%)$.

These results allow us to determine whether the joint process variability is in-control or out-of-control. It is shown that the out-ofcontrol and the in-control percentage changes by using difference values of and ARL. It was shown that there is a relationship between the value of $r$ and the out of-control percentage, the out-of-control percentage increased by increasing the value of $r$.

Test results indicate that in the high pressure stage, for example, the points $(114,118,123,128,133,134,138,140,143)$ out-of-control and the variables which causes the out-of-control signals are (X6, t2.4, X16). Also points $(151,156,161,166,167,171,173)$ out-of-control and the variables which causes the out-of-control signal are (X2, X3, t2.1, t2.4) and so on. 
It is shown that in the design of MEWMA control charts, small values of $r$ are more efficient in detecting small process mean shifts and large values of $r$ are more efficient in detecting large process mean shifts.

\section{Conclusion}

To determine whether or not the process in control, the company should choose small values of $r$ to detect small process mean shifts and choose large values of $r$ to detect large process mean shifts by using MEWMA chart.

The company should use multivariate quality control chart; MEWMA, to monitor the quality of the urea production.

\section{References}

[1] C. A. Lowry and D. C. Montgomery, A review of multivariate control charts, IIE Transactions 27 (1995), 800-810.

[2] C. A. Lowry, W. H. Woodall, C. W. Champ and S. E. Rigdon, A multivariate exponentially weighted moving average control chart, Technometrics 34 (1992), 46-53.

[3] C. B. Khoo, Increasing the sensitivity of multivariate EWMA control chart, Quality Engineering 16 (2003), 75-85.

[4] C. Fuchs and R. S. Kenett, Multivariate Quality Control Theory and Applications, Marcel Dekker, Inc., New York, 1998.

[5] F. B. Alt, Multivariate quality control, Encyclopedia of the Statistical Sciences, (Z. S. Kot, N.L. Johnson and C. R. Read eds.) 6 (1985), 111-122.

[6] F. B. Alt and N. D. Smith, Multivariate process control, Handbook of Statistics, P. R. Krishnaiah and C. R. Rao, Eds. Elsevier, 7 (1988), 333-335.

[7] G. C. Runger and S. S. Prabhu, A Markov chain model for the multivariate exponentially weighted moving averages control chart, Journal of the American Statistical Association 91 (1996), 1701-1706.

[8] H. N. Timm, Multivariate quality control using finite intersection tests, Journal of Quality Technology 28 (1996), 233-243.

[9] J. E. Jackson, Multivariate quality control, Communications in Statistic-Theory and Methods 11 (1985), 2657-2688. 
[10] J. E. Jackson and R. H. Morris, An application of multivariate quality control to photographic processing, Journal of the American Statistical Association 52 (1957), 186-199.

[11] J. F. MacGregor and T. J. Harris, Discussion of exponentially weighted moving average control schemes, Technometrics 32 (1990), 23-26.

[12] J. F. MacGregor and T. Kourti, Statistical process control of multivariate process, Control Eng. Practice 3(3) (1995), 403-414.

[13] J. M. Lucas and M. S. Saccucci, Average run length for exponentially weighted moving average control schemes using the Markov chain approach, Journal of Quality Technology 22 (1990), 154-162.

[14] K. W. Linderman and T. E. Love, Economic and economic statistical design for MEWMA control chants, Journal of Quality Technology 32 (2000), 410-417.

[15] R. L. Mason, C. W. Champ, N. D. Tracy, S. T. Wierda and J. C. Young, Assessment of multivariate process control techniques: A discussion on statistically-based process monitoring and control, Journal of Quality Technology 29 (1997), 140-143.

[16] R. L. Masson, N. D. Tracy and J. C. Young, Multivariate statistical process control with industrial application, The American Statistical Association and Society for Industrial and Applied Mathematics, (2002).

[17] S. E. Rigdon, An integral equation for the in-control average run length of a multivariate exponentially weighted moving average control chart, Journal of Statistical Computation and Simulation 52 (1995), 351-365.

[18] S. J. Wierda, Multivariate Statistical Process Control, Wolters-Noordhoff, Groningen, 1994. 